Nondestructive Assay Tests of High-Efficiency Neutron Counter (HENC) for Waste Assay and Possible Diversion Scenario

\section{RECEIVED \\ JUN 291998 \\ 0911}

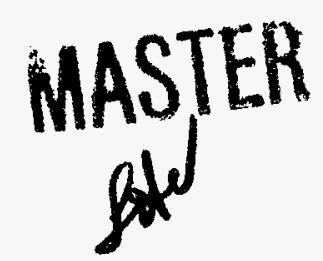

\section{DISTRIBUTION OF THIS DOCUMENT IS UNLMITED}

\section{Los Alamos}

NATIONAL LABORATORY

Los Alamos National Laboratory is operated by the University of California for the United States Department of Energy under contract W-7405-ENG-36. 
This work was supported by the US Department of Energy, Office of Safeguards and Security.

Edited by Jeff Skiby, Group CIC-1

Prepared by Karen Griggs, Group NIS- 5

An Affirmative Action/Equal Opportunity Employer

This report was prepared as an account of work sponsored by an agency of the United States Govermment. Neither The Regents of the University of California, the United States Government nor any agency thereof, nor any of their emiployees, makes any warranty, express or implied, or assumes any legal liability or responsibility for the accuracy, completeness, or usefulness of any information, apparatus, product, or process disclosed, or represents that its use toould not infringe privately owned rights. Reference herein to any specific commercial product, process, or service by trade name, trademark, manufacturer, or othervise, does not necessarily constitute or imply its endorsement, recommendation, or favoring by The Regents of the University of California, the United States Government, or any agency thereof. The ziews and opinions of authors expressed herein do not necessarily state or reflect those of The Regents of the University of California, the United States Government, or any agency thereof. Los Alamos National Laboratory strongly supports acadentic freedom and a researcher's right to publish; as an institution, however, the Laboratory does not endorse the vieupoint of a publication or guarantee its technical correctness. 


\section{DISCLAIMER}

This report was prepared as an account of work sponsored by an agency of the United States Government. Neither the United States Government nor any agency thereof, nor any of their employees, make any warranty, express or implied, or assumes any legal liability or responsibility for the accuracy, completeness, or usefulness of any information, apparatus, product, or process disclosed, or represents that its use would not infringe privately owned rights. Reference herein to any specific commercial product, process, or service by trade name, trademark, manufacturer, or otherwise does not necessarily constitute or imply its endorsement, recommendation, or favoring by the United States Government or any agency thereof. The views and opinions of authors expressed herein do not necessarily state or reflect those of the United States Government or any agency thereof. 


\section{DISCLAIMER}

Portions of this document may be illegible electronic image products. Images are produced from the best available original document. 
Nondestructive Assay Tests of High-Efficiency Neutron Counter (HENC) for Waste Assay and Possible Diversion Scenario

D. R. Mayo

H. O. Menlove

J. M. Pecos

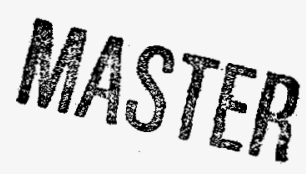

DISTRIBUTION OF TMIS DOCUAENT IS UNUMTTED 


\title{
NONDESTRUCTIVE ASSAY TESTS OF HIGH-EFFICIENCY NEUTRON COUNTER (HENC) FOR WASTE ASSAY AND POSSIBLE DIVERSION SCENARIO
}

by

D. R. Mayo, H. O. Menlove, and J. M. Pecos

\begin{abstract}
An advanced passive neutron counter, the high-efficiency neutron counter (HENC), has been used to measure plutonium content in $200-\mathrm{L}$ waste drums. The $\mathrm{HENC}$ was designed with the ${ }^{252} \mathrm{Cf}$ "add-a-source" (AS) feature to improve accuracy over a wide range of waste matrix materials. The current implementation allows for passive neutron coincidence counting, AS analysis, and multiplicity analysis. Passive neutron assay of "typical" waste containers is intrinsically more accurate than active neutron techniques because of the penetrability of the spontaneous fission neutrons originating from within the waste matrix. In addition, the HENC is designed as a slightly undermoderated detector to be less sensitive to low loading of hydrogen-bearing matrices. The following paper considers the applicability of three different nondestructive assay methods for analysis of waste drums and the flagging of possible diversions in waste drums. The ${ }^{252} \mathrm{Cf} \mathrm{AS}$ method, multiplicity counting, and a bounded-parameter multiplicity analysis are presented with areas of applicability.
\end{abstract}

\section{INTRODUCTION}

The measurement of plutonium content in waste containers is required prior to longterm storage or shipment. The high-efficiency neutron counter (HENC) was developed as part of a cooperative research and development agreement (CRADA) between the Department of Energy (DOE) and Canberra Industries to measure the plutonium content in 200-L waste drums. ${ }^{1}$ The initial characterization of the detector and performance evaluation is described elsewhere. ${ }^{2}$

The HENC consists of high-density polyethylene (HDPE) with 10-cm detector banks backed by $30-\mathrm{cm}$-thick HDPE shielding. The sample cavity is designed to accommodate up to $200-\mathrm{L}$ drums. The $200-\mathrm{L}$ sample drums are brought into the detector via rollers onto a rotating stand. The detector has doors on opposite sides for ease of loading and to allow for placement in an industrial setting. A full description of the system can be found in the HENC Hardware Manual. ${ }^{3}$ 
The HENC uses totals, coincidence, multiplicity, and the ${ }^{252} \mathrm{Cf}$ "add-a-source" (AS) method to determine plutonium mass in a sample. The passive system records the multiplicities measured from the waste drums and calculates the single (S), double (D), and triple (T) counting rates. The passive neutron counting relies on the spontaneous fission neutrons from the sample. The signal level, however, of spontaneous fission neutrons is low, limiting the sensitivity of the system. The multiplicity method uses the $\mathrm{S}, \mathrm{D}$, and $\mathrm{T}$ rates to solve the point model equations and determine the plutonium mass. The AS feature uses an external ${ }^{252} \mathrm{Cf}$ source to interrogate the sample. The dependence of neutron coincidence counting on the waste matrix is minimized by the use of the AS correction. For all of the methods considered, it is necessary to know the plutonium isotopics to convert measured ${ }^{240} \mathrm{Pu}$ effective mass to total plutonium.

Three methods of nondestructive assay (NDA) for 200-L waste drums are considered with regards to applications in waste assay, performance demonstration program (PDP) trials, and diversion scenarios. A brief discussion of the AS, multiplicity, and bounded-parameter multiplicity analysis NDA methods are given, followed by a presentation of the results.

\section{A. Add-A-Source}

The AS method ${ }^{4}$ measures the matrix perturbation to the counting rate from a small ${ }^{252} \mathrm{Cf}$ source $\left(\approx 3 \times 10^{4} \mathrm{n} / \mathrm{s}\right)$ on the outside of the sample. This information is used to correct for the matrix perturbation inside the sample.

The HENC, as shown in Fig. 1, positions the ${ }^{252} \mathrm{Cf}$ source at three locations along the side of the drum. The drum rotates to give an averaged effect. The sample matrix has two primary effects on the neutrons. The neutrons are reduced in energy by scattering reactions and low-energy neutrons are captured by the materials. As shown in Fig. 2, hydrogen-bearing materials tend to decrease the observed count rate, while metal-bearing materials tend to enhance the count rate. 


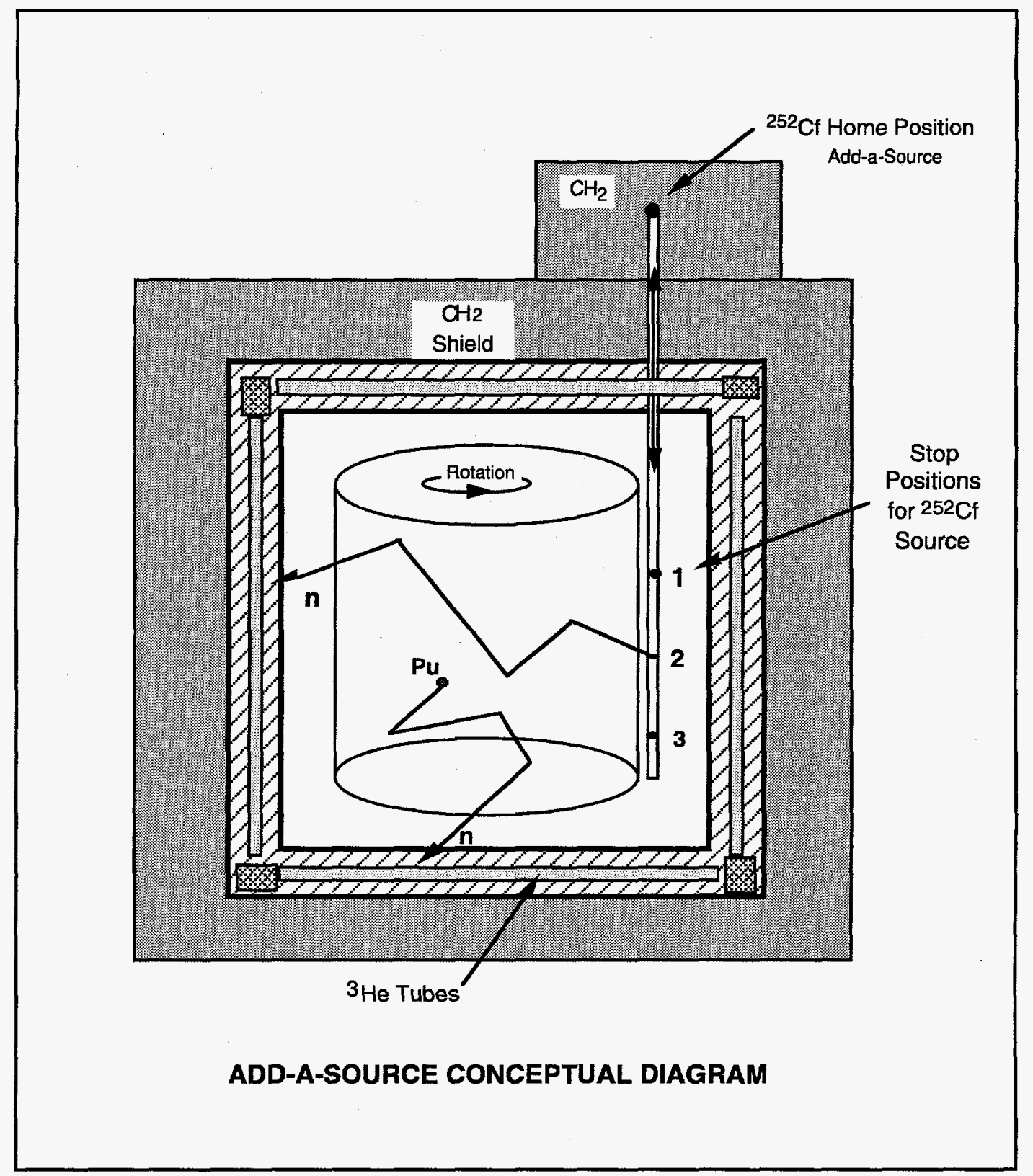

Fig. 1. HENC conceptual diagram with the ${ }^{252} C F$ AS feature. 


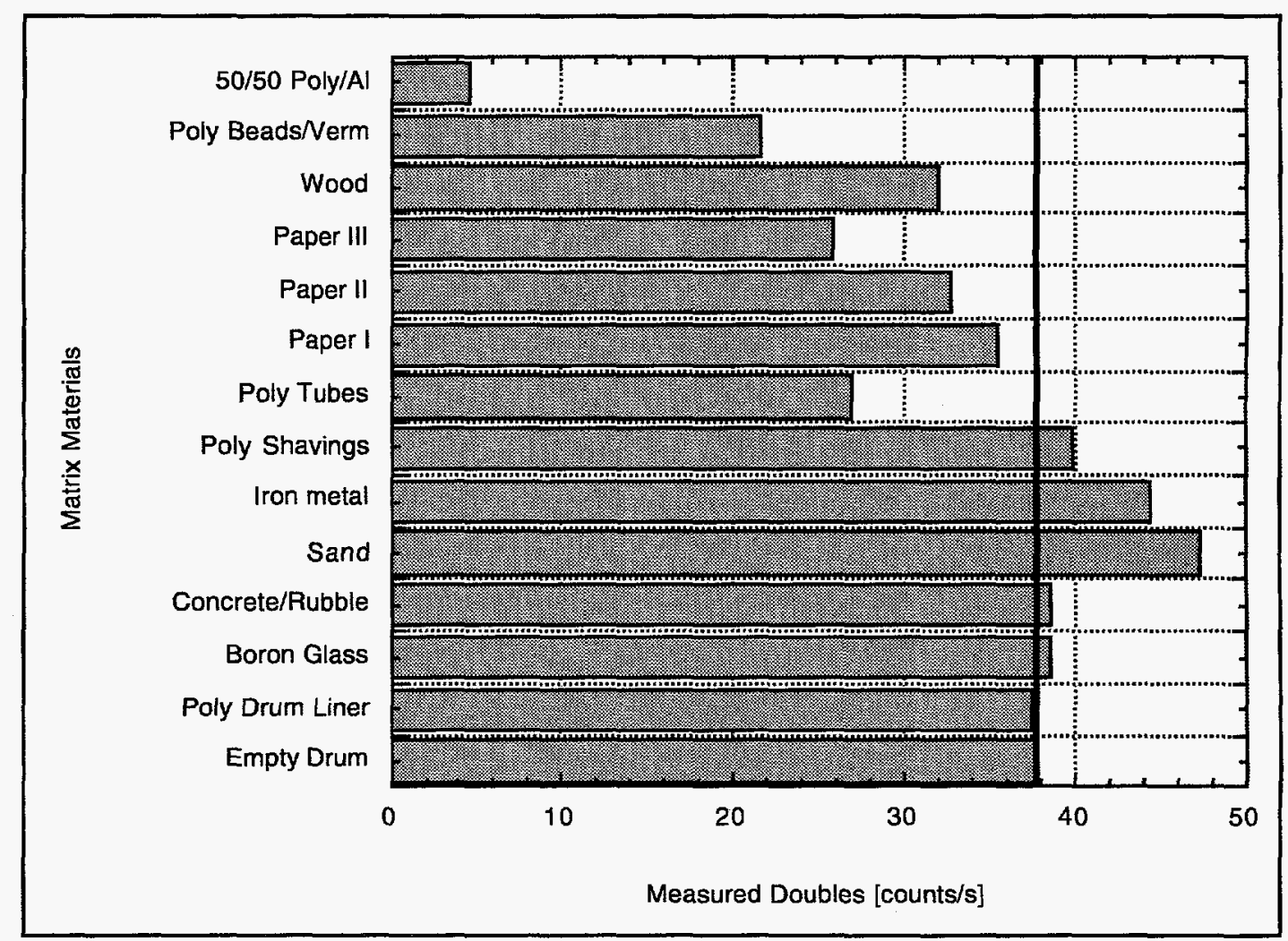

Fig. 2. Effects of matrix loading on measured double count rate from $F Z C-158$ for the HENC.

Matrices of glass, concrete/rubble, sand, iron, various densities of polyethylene, paper, and wood were used to calculate the AS perturbation. The AS perturbation is the measured change in the $\mathrm{D}$ rate of ${ }^{252} \mathrm{Cf}$ source exterior to the drum due to the presence of the waste drum and its contents. The AS perturbation corresponds to a correction factor resulting in a "corrected doubles rate." The corrected doubles rate, $\mathrm{D}_{c}$, is related to the ${ }^{240} \mathrm{Pu}$ effective mass. The mass determination relies on calibration of the detector in the passive mode. One possible weakness of the AS method is in the assumption that the plutonium is uniformly distributed in the drum.

\section{B . Multiplicity Analysis}

The analysis of the drums using multiplicity counting assumes the point model $^{5}$ and sets the neutron self multiplication to $1(M=1)$. The point model relates the observed $S, D$, and $\mathrm{T}$ rates to the ${ }^{240} \mathrm{Pu}$ effective mass $\left(\mathrm{m}_{\mathrm{Pu} 240 \mathrm{e}}\right)$, the detector efficiency $(\varepsilon)$, the neutron self multiplication $(\mathrm{M})$, and the $(\alpha, n)$ to spontaneous fission ratio $(\alpha)$. 
Typically, one measures an average efficiency with a calibrated standard and calculates the other three parameters. For the cases of waste, it is assumed that the self-multiplication is small $(M \approx 1)$. This allows for solution of $\varepsilon, \alpha$, and $\mathrm{m}_{\mathrm{Pu} 2400}$, where the matrix effects are taken into account by the change in detector efficiency.

The multiplicity method has an advantage in identifying diversions as it relies on the $\mathrm{S}$, $D$, and $T$ rates (which go as $\varepsilon: \varepsilon^{2}: \varepsilon^{3}$ ) to calculate the $\mathrm{m}_{\mathrm{P} u 240 \mathrm{e}}$, whereas the AS method relies only on the corrected $\mathrm{D}$ rate of the sample. Changes in the detector efficiency are due to matrix effects and are shown by changes in the ratios of the S:D:T counting rates, thus resulting in an indicator of shielding. The efficiency measured by multiplicity counting has the advantage in that it directly measures the detection efficiency of each neutron escaping the drum. A sample having localized shielding and/or nonuniform plutonium distributions are not a problem for the multiplicity method. The primary limitation is that low plutonium mass samples, which is typical of waste, will result in poor counting statistics unless long counting times are used.

\section{Bounded Parameter Multiplicity Analysis}

The limitations of the AS and multiplicity methods for detection of diversion lead to the consideration of an alternative method, the bounded-parameter multiplicity analysis (BPMA). The BPMA method does not use the point model equations with $M=1$, but incorporates the calibration curves that relate $\mathrm{m}_{\mathrm{Pu} 240 \mathrm{e}}$ to $\mathrm{D}$ and $\mathrm{T}$ coincidence rates. The calibration curves for $\mathrm{S}$, $\mathrm{D}$, and $\mathrm{T}$ to $\mathrm{m}_{\mathrm{Pu} 240 \mathrm{e}}$ for the HENC were measured using plutonium standards including mixed oxide and $\mathrm{PuO}_{2}$ powder samples. The calibration ${ }^{2}$ gives a fit of the data for $\mathrm{D}$ and $\mathrm{T}$ rates to $\mathrm{m}_{\mathrm{Pu} 240 \mathrm{e}}$. The neutron multiplication was negligible for the calibration standards used (i.e., $\mathrm{M} \approx$ 1). The BPMA generates a $D_{c}$ using the $D$ and $T$ counting rates, which is related to $m_{P u 240 e}$ $\left(m_{P u 240 e} \propto D_{\mathrm{c}}\right)$. The correction factor is of the form

$$
C F=1+f\left(\frac{D}{T}\right),
$$

which results in a lower error/uncertainty for the mass than the multiplicity equation results for mass.

\section{Backgrounds}

For all of the analysis methods used with passive neutron counting, it is necessary to measure background levels with similarly loaded 55 -gal. drums because the contents of the drum affect the background level to be subtracted. A metal-containing drum will increase background levels whereas hydrocarbons decrease the background, both affecting the $\mathrm{D}$ rate and inducing a bias. For the HENC, Table I contains the data measured for various matrices and Figs. 3 and 4 compare the results of $\mathrm{D}$ and $\mathrm{T}$ background effects respectively. 


\begin{tabular}{|l|c|c|c|c|}
\hline \multicolumn{5}{|c|}{$\begin{array}{l}\text { Table I. Cosmic-Ray Backgrounds as Measured in HENC as a Function } \\
\text { of 200-L Drum }\end{array}$} \\
\hline \multicolumn{1}{|c|}{ Matrix } & $\begin{array}{c}\text { Matrix Mass } \\
(\mathrm{kg})\end{array}$ & $\begin{array}{c}\text { Singles } \\
(\text { counts/s })\end{array}$ & $\begin{array}{c}\text { Doubles } \\
(\text { counts/s })\end{array}$ & $\begin{array}{c}\text { Triples } \\
\text { (counts/s })\end{array}$ \\
\hline Empty Drum & 0.0 & 23.67 & 2.61 & 0.551 \\
\hline Paper & 53.9 & 22.58 & 2.23 & 0.437 \\
\hline Polyethylene Beads with Vermiculite & 66.0 & 22.25 & 2.24 & 0.460 \\
\hline Polyethylene Tubes & 32.5 & 22.99 & 2.30 & 0.463 \\
\hline Polyethylene Shavings & 7.2 & 23.34 & 2.40 & 0.492 \\
\hline Wood & 51.0 & 23.44 & 2.40 & 0.521 \\
\hline Boron Glass & 173.0 & 24.54 & 2.94 & 0.668 \\
\hline Concrete Rubble & 220.0 & 26.05 & 2.97 & 0.678 \\
\hline Graphite Block & 126.6 & 26.96 & 3.13 & 0.743 \\
\hline Sand & 290.0 & 27.53 & 3.68 & 1.003 \\
\hline Iron & 196.0 & 30.38 & 5.70 & 2.191 \\
\hline
\end{tabular}

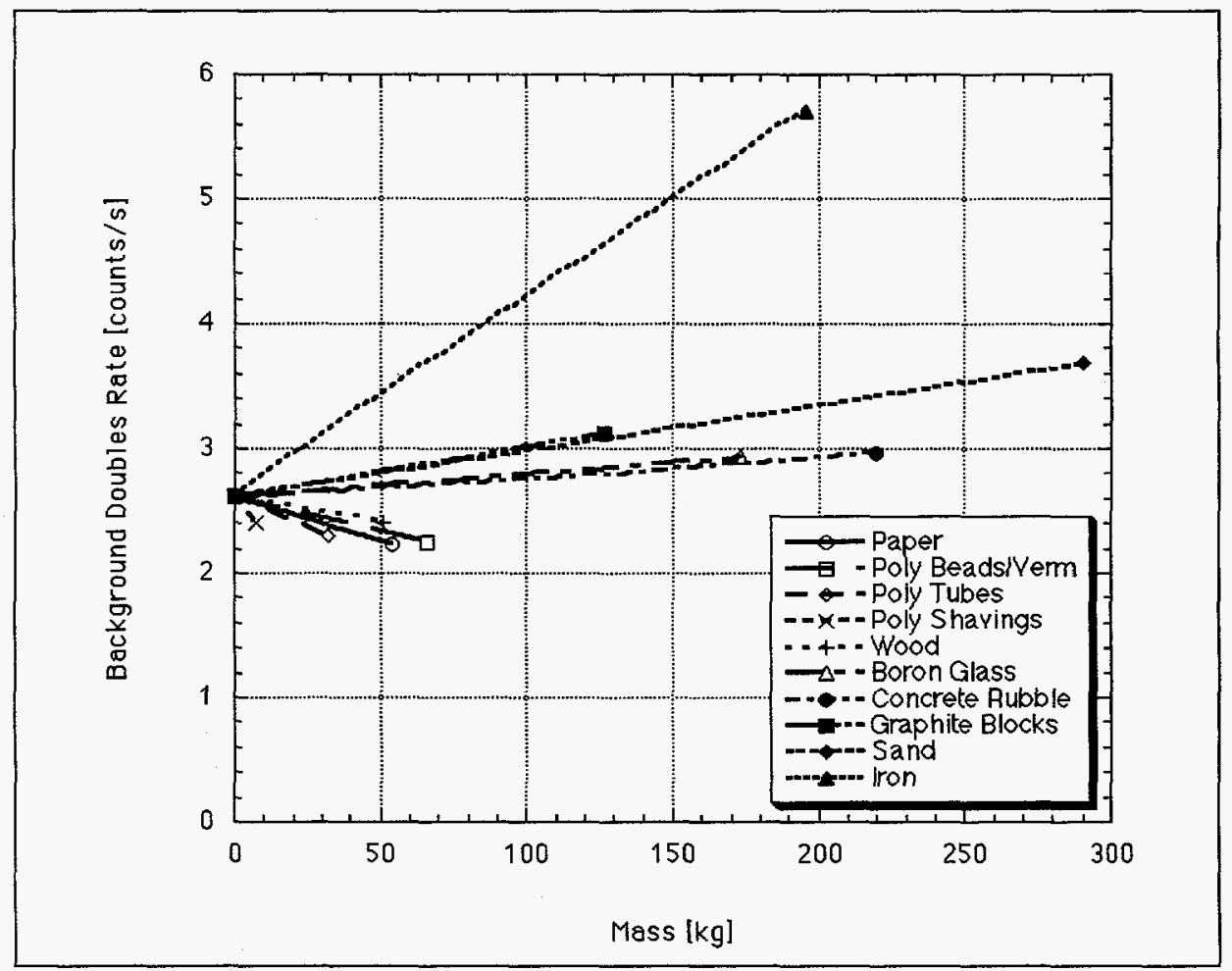

Fig. 3. Doubles background rate for the HENC as a function of matrix type and mass in the 200-L drum. 


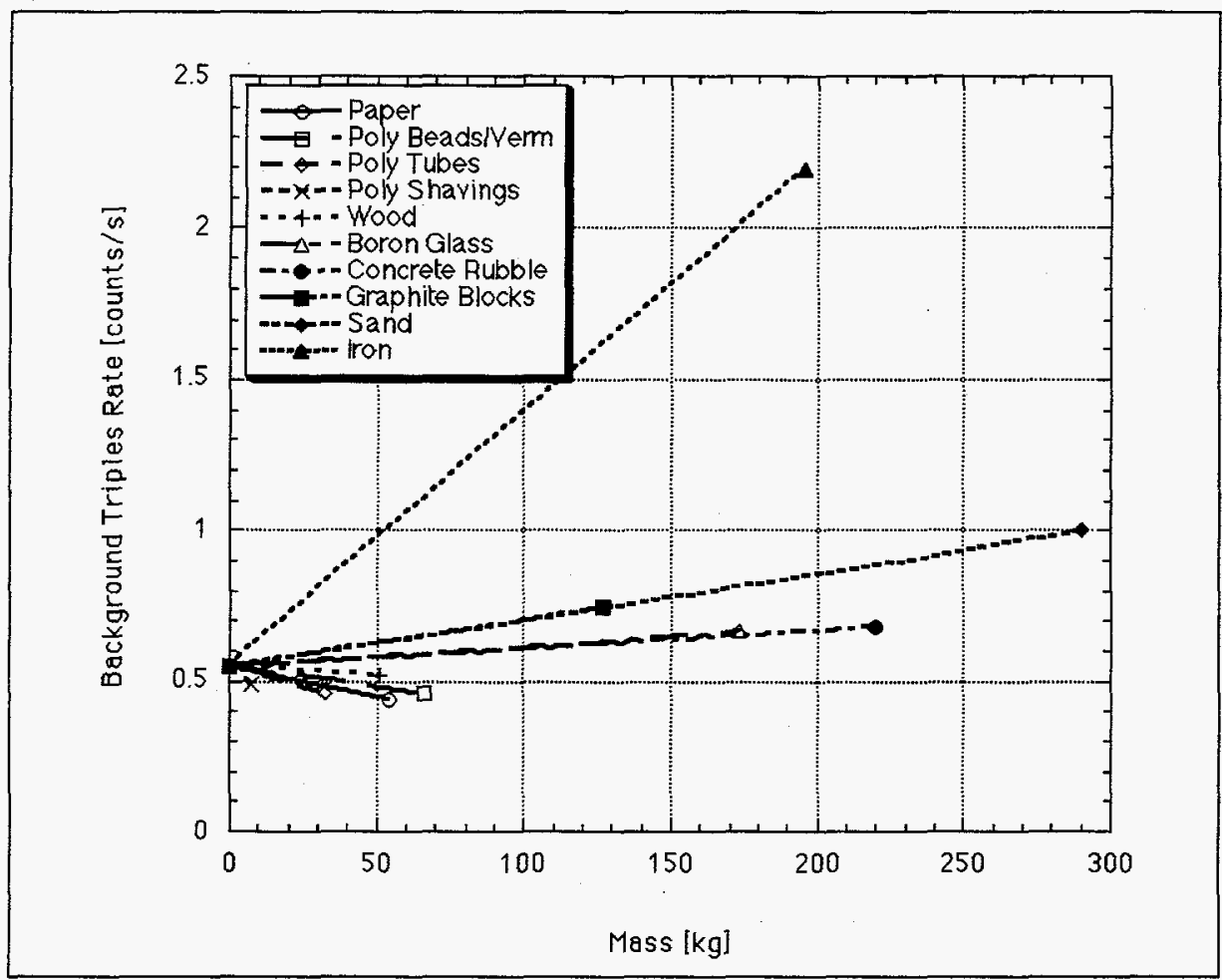

Fig. 4. Triples background rates for the HENC as a function of matrix type and mass in the 200-L drums.

\section{E. Applications of Methods}

The three analysis methods are compared for applications to waste assay, including the PDP cycles, and specifically the possible diversion of material from any location where appreciable amounts of special nuclear material, especially plutonium, are accessed by workers. The HENC with AS has the capability of flagging local shielding by comparing the resulting AS measured D ratio to an empty drum at the three points along the outside of the drum. Large fluctuations in the ratios at the three points would indicate a possibly stratified matrix and possibly local shielding. The multiplicity analysis is best suited for determining local shielding of a single source, but suffers from poor counting statistics with low mass samples. The BPMA produces results with smaller uncertainty than multiplicity for the same measurement times, when using the $\mathrm{D}$ and $\mathrm{T}$ rates to correct for matrix effects. 


\section{ANALYSIS METHODS}

Data were recorded for ${ }^{252} \mathrm{Cf}$ and plutonium samples for various matrix loadings to arrive at a volume and/or radial averaged result. $\mathrm{S}, \mathrm{D}$, and $\mathrm{T}$ rates from the multiplicity register, along with the $\mathrm{D}$ rates of the AS at three vertical positions, were recorded for each setup. Additional data were recorded with plutonium standards which consisted of the plutonium oxide powders mixed in diatomaceous earth. The data were taken using the CANBERRA WM3100 Series/HENC Passive Neutron Coincidence Drum Counter with the Neutron Coincidence Counting software, Windows NCC. The HENC Detector Parameters are listed in Table II. The data were then analyzed using the three methods described in the previous sections and detailed below. The ${ }^{252} \mathrm{Cf}$ data, in addition to measuring the detector parameters, were used as a reference calibration source by being placed in the center of the detector.

\begin{tabular}{|c|c|}
\hline Table II. HENC Detector & Parameters $^{2}$ \\
\hline Detector Parameter & Value \\
\hline High Voltage & $1720 \mathrm{~V}$ \\
\hline Pre-Delay & $3.0 \mu \mathrm{s}$ \\
\hline Neutron Die-Away & $50 \mu \mathrm{s}$ \\
\hline Coincidence Gate Length & $128 \mu \mathrm{s}$ \\
\hline Deadtime (a) & $0.50 \mu \mathrm{s}$ \\
\hline$\left(\mathrm{b} \times 10^{-6}\right)$ & $0.161 \mu \mathrm{s}$ \\
\hline Multiplicity Deadtime & $0.147 \mu \mathrm{s}$ \\
\hline Neutron Efficiency: ${ }^{252} \mathrm{Cf}$ & $30 \%$ \\
\hline${ }^{240} \mathrm{Pu}$ & $31 \%$ \\
\hline
\end{tabular}

The passive neutron coincidence calibration data for the HENC are listed in Table III, and the resulting calibration curves relating $\mathrm{D}$ and $\mathrm{T}$ to $\mathrm{m}_{\mathrm{Pu} 240 \mathrm{e}}$ are shown in Fig. 5 .

\begin{tabular}{|c|c|c|c|c|c|c|}
\hline Table III. HENC & Passive & Neutron $\mathrm{C}$ & Counting $\mathrm{C}$ & Calibration & Data $^{2}$ & \\
\hline Sample & $\begin{array}{c}\mathrm{m}_{\mathrm{Pu24de}} \\
(\mathrm{g})\end{array}$ & $\begin{array}{l}\mathrm{T} \\
(\mathrm{s})\end{array}$ & $\begin{array}{c}\mathrm{S} \\
\text { (counts } / \mathrm{s})\end{array}$ & $\begin{array}{c}\mathrm{D} \\
\text { (counts/s) }\end{array}$ & $\begin{array}{c}\mathrm{T} \\
\text { (counts/s) }\end{array}$ & $\begin{array}{l}\text { Alpha } \\
(\alpha)\end{array}$ \\
\hline A1-066, 081, 078 & 0.161 & $60 \times 30$ & 98.9 & 8.86 & 0.971 & 1.013 \\
\hline A1-066-078, 081, 089, 119 & 0.243 & $60 \times 30$ & 143.7 & 13.12 & 1.42 & 1.013 \\
\hline FZC-158 & 0.705 & $60 \times 30$ & 246.8 & 37.87 & 4.3 & 0.142 \\
\hline A1-066, 078,081, 089, 119, FZC-158 & 0.948 & $60 \times 30$ & 390.5 & 50.98 & 5.41 & 0.365 \\
\hline${ }^{252} \mathrm{Cf}$, CR-6 Centered $(96 / 11 / 01)$ & N.A. & $20 \times 30$ & 2120.0 & 646.40 & 118.1 & $\mathrm{NA}$ \\
\hline PDP1-3.0 & 0.1833 & $40 \times 30$ & 158.5 & 9.80 & 1.25 & $0.787^{b}$ \\
\hline PDP1-3.0+0.5 & 0.2138 & $59 \times 30$ & 186.2 & 11.94 & 1.88 & $0.787^{\mathrm{b}}$ \\
\hline PDP1-3.0+0.5+0.1 ${ }^{\mathrm{a}}$ & 0.2199 & $513 \times 10$ & 189.4 & 11.97 & 1.37 & $0.787^{\mathrm{b}}$ \\
\hline
\end{tabular}




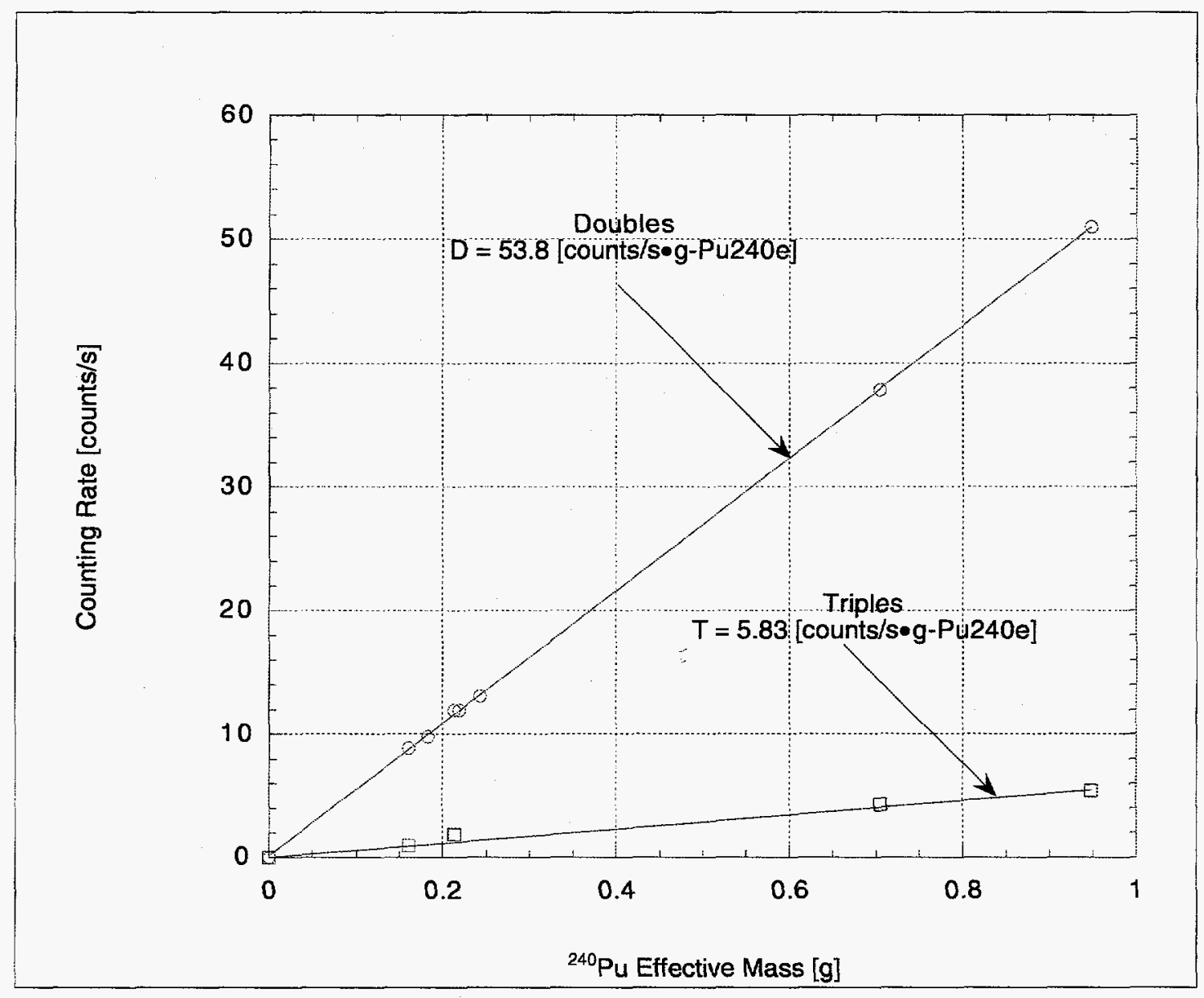

Fig. 5. D and T counting rate calibration of HENC for plutonium samples listed in Table II.

\section{A. Add-A-Source}

The AS analysis uses a ${ }^{252} \mathrm{Cf}$ source external to the waste drum to correct for the effects of the matrix on the neutrons generated in the drum. The HENC measures the D rate due to the ${ }^{252} \mathrm{C}$ f source at three positions along the exterior of the drum and calculates an average $(D)$. A ratio of the average $\mathrm{D}$ rate to the $\mathrm{D}$ rate measured for an empty drum $\left(D_{0}\right)$ is used to correct the passive doubles. The matrices used to generate the calibration are described in Table IV. The effect on the average $\mathrm{D}$ of the external ${ }^{252} \mathrm{Cf}$ source are related to the effect on neutrons passing from inside the matrix to the detector. A plutonium source is placed inside the test matrix materials at known locations to generate a volume or radially averaged matrix perturbation for the neutrons. The resulting data is presented in Table V. 


\begin{tabular}{|l|c|l|}
\hline \hline \multicolumn{2}{|c|}{ Table IV. Matrix Loadings of $\begin{array}{l}\text { 200-L Drums Used for HENC Add-a-Source } \\
\text { Calibration }\end{array}$} \\
\hline Sample Drum Loading & $\begin{array}{l}\text { Mass of Matrix } \\
\mathrm{kg})\end{array}$ & Description \\
\hline Empty Drum & 0.0 & Empty metal drum \\
\hline $\begin{array}{l}\text { Polyethylene Drum } \\
\text { Liner }\end{array}$ & 9.1 & 5 -mm-thick polyethylene liner on inside wall of drum \\
\hline Boron Glass & 173.0 & Raschig rings \\
\hline Concrete/Rubble & 220.0 & High-density concrete block mixed with $10 \mathrm{~kg}$ paper \\
\hline Sand & 290.0 & Dry sand \\
\hline Iron Metal & 196.0 & Iron pieces $(\approx 170 \mathrm{~kg})$ mixed with aluminum $(\approx 26 \mathrm{~kg})$ \\
\hline Polyethylene Shavings & 7.2 & Low-density polyethylene shavings \\
\hline Polyethylene Tubes & 32.5 & Chopped polyethylene tubes \\
\hline Paper I & 38.4 & Low-density paper \\
\hline Paper II & 53.9 & Medium-density paper \\
\hline Paper mI & 71.0 & High-density paper \\
\hline Wood & 51.0 & Wood pieces \\
\hline Polyethylene Beads/ & 66.0 & $\begin{array}{l}\text { Polyethylene beads (41 kg) plus vermiculite }(22 \mathrm{~kg}) \text { plus } \\
\text { borax } \approx 31 \text { kg) }\end{array}$ \\
\hline Vermiculite & & \\
\hline
\end{tabular}

\begin{tabular}{|c|c|c|c|c|c|c|c|c|}
\hline & Table & V. Ad & 1-a-Sot & ree Ca & ibration & Data $^{2}$ & & \\
\hline Sample & $\mathrm{S}_{\mathrm{av}}$ & $\mathrm{D}_{\mathrm{av}}$ & $\mathrm{T}_{\mathrm{av}}$ & $S_{\mathrm{o}} / \mathrm{S}$ & $\mathrm{D}_{0} / \mathrm{D}$ & $\mathrm{T}_{0} / \mathrm{T}$ & $\mathrm{AS} \mathrm{D}_{\mathrm{av}}$ & $\mathrm{AS} \mathrm{D}_{0} \mathrm{D}$ \\
\hline Empty Drum & 246.8 & 37.87 & 4.11 & 1.000 & 1.000 & 1.000 & 10030 & 1.000 \\
\hline Poly Drum Liner & 248.3 & 37.55 & 3.97 & 0.994 & 1.009 & 1.035 & 10148 & 0.988 \\
\hline Boron Glass & 237.4 & 38.87 & 4.36 & 1.040 & 0.974 & 0.943 & 9778 & 1.026 \\
\hline Concrete/Rubble & 257.8 & 38.85 & 4.35 & 0.957 & 0.975 & 0.945 & 9925 & 1.011 \\
\hline Sand & 265.3 & 48.45 & 6.55 & 0.930 & 0.782 & 0.627 & 10985 & 0.913 \\
\hline Iron Metal & 259.0 & 47.54 & 7.84 & 0.953 & 0.797 & 0.524 & 10696 & 0.938 \\
\hline Poly Shavings & 258.4 & 39.68 & 4.61 & 0.955 & 0.954 & 0.892 & 10055 & 0.998 \\
\hline Poly Tubes & 231.6 & 26.53 & 2.35 & 1.066 & 1.427 & 1.749 & 7540 & 1.330 \\
\hline Paper I & 253.8 & 35.09 & 3.36 & 0.972 & 1.079 & 1.223 & 9278 & 1.081 \\
\hline Paper II & 246.6 & 32.33 & 2.98 & 1.001 & 1.171 & 1.379 & 8500 & 1.180 \\
\hline Paper III & 228.1 & 25.33 & 2.20 & 1.082 & 1.495 & 1.868 & 7711 & 1.301 \\
\hline Wood & 247.7 & 31.75 & 2.81 & 0.996 & 1.193 & 1.463 & 8594 & 1.167 \\
\hline \begin{tabular}{|l} 
Poly Beads/ \\
Vermiculite \\
\end{tabular} & 202.2 & 21.23 & 1.30 & 1.221 & 1.784 & 3.162 & 6942 & 1.445 \\
\hline $\begin{array}{l}\text { Half Poly/ Half } \\
\text { Aluminum }\end{array}$ & 100.7 & 4.58 & 0.13 & 2.451 & 8.269 & 31.615 & 7066 & 1.419 \\
\hline
\end{tabular}


The volume-averaged plutonium $D$ perturbation $\left(\Delta y_{D}\right)$ was approximated with a thirdorder polynomial and is given by

The fit coefficients are given by

$$
\Delta y_{D}=a_{0}+a_{1} \delta+a_{2} \delta^{2}+a_{3} \delta^{3}
$$

$$
\begin{aligned}
& a_{0}=-0.0131, \\
& a_{1}=1.378, \\
& a_{2}=-1.916, \text { and } \\
& a_{3}=5.86 ;
\end{aligned}
$$

and the AS perturbation is represented as $\delta=\left(D_{0} / D\right)-1$, where $D_{0}$ is the measured D rate of the ${ }^{252} \mathrm{Cf}$ source with an empty drum and $D$ is the measured $\mathrm{D}$ rate with the sample drum.

The resulting relationship is a single curve from AS perturbation $(\delta)$ to plutonium D $\left(\Delta y_{D}\right)$ or mass perturbation, as shown in Fig. 6. As implemented, an additional constraint is placed upon the perturbations, for $|\delta| \leq 0.02$ then $\Delta y_{D} \equiv 0$, to handle the fluctuations near zero correction.

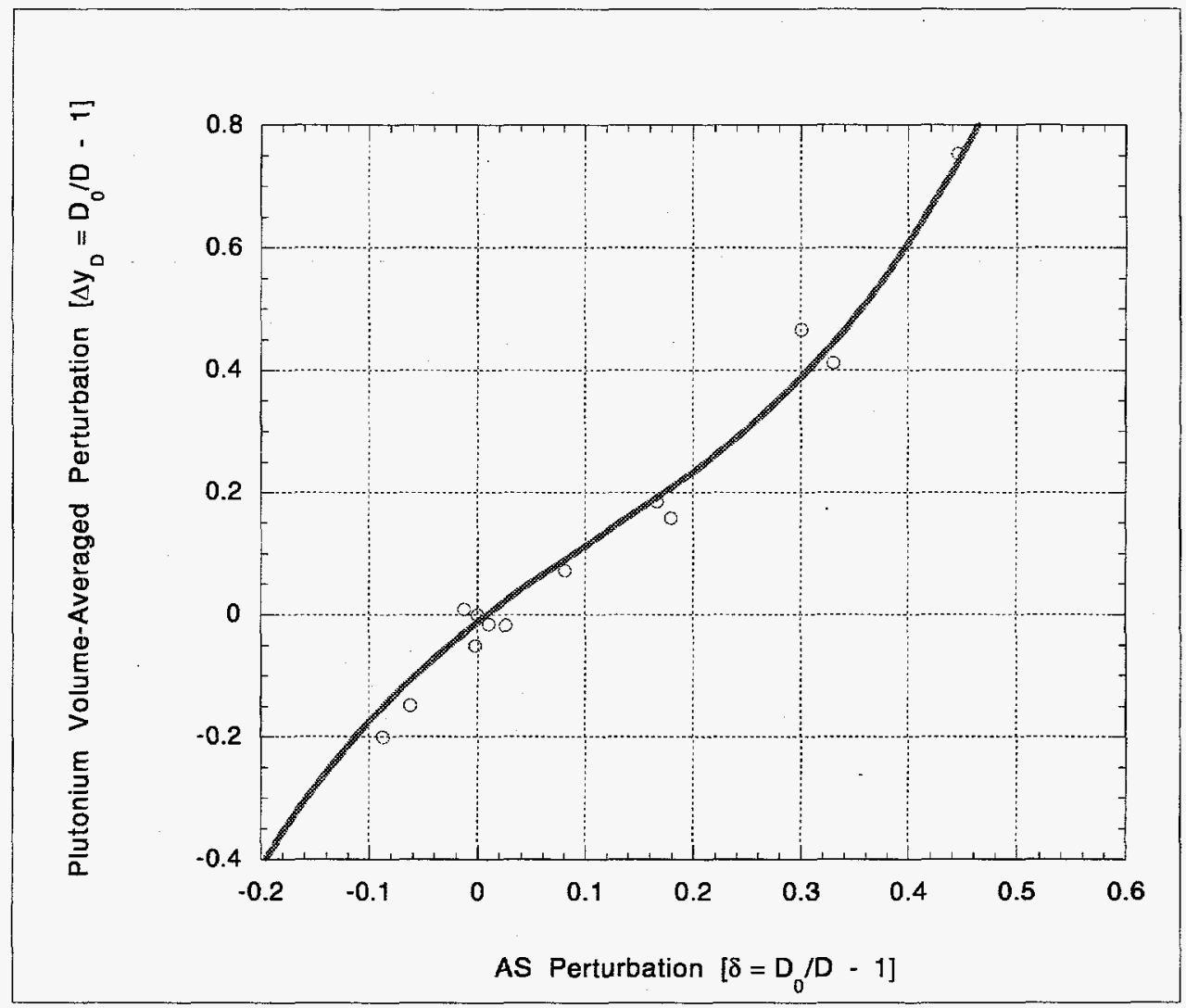

Fig. 6. AS calibration function for the matrix materials listed in Table $V$. The horizontal axis is the perturbation of the external $A S$ and the vertical is the volume-averaged perturbation of the ${ }^{240} \mathrm{Pu}$ effective $D$ rate. 
The AS corrected $D$ rate $\left(D_{c}\right)$ is given by

$$
D_{c}=C F \times D \text {, where } C F=1+\Delta y_{D} \text {. }
$$

The $\mathrm{m}_{\mathrm{Pu} 240 \mathrm{e}}$ is then calculated using a linear calibration curve of $\mathrm{m}_{\mathrm{Pu} 240 \mathrm{e}} \mathrm{vs} \mathrm{D}$ and is given by

$$
D_{c}=a m_{P u 240 e},
$$

where $a$ is given in Fig. 5 as 53.8 counts/s $/$ g-Pu240e and the results of the calibration given in Table VI. The spread in the $\mathrm{D}$ is reduced from $21 \%$ to $3 \%$. The $\mathrm{m}_{\mathrm{Pu} 240 \mathrm{e}}$ is calculated using (Eq. 3) and is in good agreement with the mass of FZC $-158(0.705-\mathrm{g})$.

\begin{tabular}{|l|c|c|c|c|c|c|}
\hline \hline \multicolumn{7}{|c|}{ Table VI. Add-a-Source Corrected D Rate ${ }^{2}$} \\
\hline Sample & $\mathrm{D}_{\text {avg }}$ & $\mathrm{D}_{\mathrm{o}} / \mathrm{D}$ & $\mathrm{AS} \mathrm{D}_{\mathrm{o}} \mathrm{D}$ & $\mathrm{CF}$ & $\mathrm{D}_{\mathrm{C}}$ & $\mathrm{m}_{\mathrm{Pu} 240 c}$ \\
\hline Empty Drum & 37.87 & 1.000 & 1.000 & 1.000 & 37.870 & 0.704 \\
\hline Poly Drum Liner & 37.55 & 1.009 & 0.988 & 1.000 & 37.550 & 0.698 \\
\hline Boron Glass & 38.87 & 0.974 & 1.026 & 1.005 & 39.064 & 0.726 \\
\hline Concrete/Rubble & 38.85 & 0.975 & 1.011 & 1.000 & 38.850 & 0.722 \\
\hline Sand & 48.45 & 0.782 & 0.913 & 0.845 & 40.940 & 0.761 \\
\hline Iron Metal & 47.54 & 0.797 & 0.938 & 0.892 & 42.406 & 0.788 \\
\hline Poly Shavings & 39.68 & 0.954 & 0.998 & 1.000 & 39.680 & 0.738 \\
\hline Poly Tubes & 26.53 & 1.427 & 1.330 & 1.437 & 38.124 & 0.709 \\
\hline Paper I & 35.09 & 1.079 & 1.081 & 1.069 & 37.511 & 0.697 \\
\hline Paper II & 32.33 & 1.171 & 1.180 & 1.190 & 38.473 & 0.715 \\
\hline Paper III & 25.33 & 1.495 & 1.301 & 1.377 & 34.879 & 0.648 \\
\hline Wood & 31.75 & 1.193 & 1.167 & 1.172 & 37.211 & 0.692 \\
\hline $\begin{array}{l}\text { Poly Beads/ } \\
\text { Vermiculite }\end{array}$ & 21.23 & 1.784 & 1.445 & 1.750 & 37.153 & 0.691 \\
\hline & & & & & & \\
\hline Mean & 35.47 & & & & 38.44 & 0.714 \\
\hline $\begin{array}{l}\text { Std. Dev. } \\
\text { (counts/s) }\end{array}$ & 8.03 & & & & 1.87 & 0.035 \\
\hline Std. Dev. (\%) & 22.65 & & & & 4.87 & 4.867 \\
\hline
\end{tabular}

\section{B . Multiplicity Analysis}

The multiplicity analysis, in this case, assumes the point model equations with $\mathbf{M}=1$ (i.e., nonmultiplying sample with low levels of plutonium and/or dispersed throughout volume). Typically the detector efficiency is fixed and a solution is found for the selfmultiplication $(M)$, the $(\alpha, n)$ to spontaneous fission rate $(\alpha)$, and the $\mathrm{m}_{\mathrm{Pu} 240 \mathrm{e}}$. The multiplicity analysis relies on point model equations ${ }^{6}$ for the passive case and are given by 


$$
\begin{aligned}
& S=F \varepsilon v_{\mathrm{s} 1}(1+\alpha) \\
& D=F \varepsilon^{2} \frac{f_{d}}{2} M^{2}\left[v_{s 2}+\left(\frac{M-1}{v_{\mathrm{i} 1}-1}\right) v_{\mathrm{s} 1}(1+\alpha) v_{\mathrm{i} 2}\right] \text {, and } \\
& T=F \varepsilon^{3} \frac{f_{t}}{6} M^{3}\left\{v_{\mathrm{s} 3}+\left(\frac{M-1}{v_{\mathrm{i} 1}-1}\right)\left[3 v_{\mathrm{s} 2} v_{\mathrm{i} 2}+v_{\mathrm{s} 1}(1+\alpha) v_{\mathrm{i} 3}\right]+3\left(\frac{M-1}{v_{\mathrm{i} 1}-1}\right) v_{\mathrm{s} 1}(1+\alpha) v_{\mathrm{i} 2}^{2}\right\}
\end{aligned}
$$

where

$$
\begin{array}{lll}
S & = & \text { the singles rate } \\
D & = & \text { the doubles rate, } \\
T & = & \text { the triples rate, } \\
m_{P u 240 e} & = & \text { the effective }{ }^{240} \mathrm{Pu} \text { mass, } \\
F & = & \text { the plutonium fission rate, } m_{P u 240 e} \times 479, \\
\varepsilon & = & \text { the neutron detection efficiency, } \\
f_{d} & = & \text { the fraction of neutron events in the doubles gate, } f_{d}=\mathrm{e}^{-P D / \tau_{d}}\left(1-\mathrm{e}^{-G / \tau_{d}}\right), \\
f_{t} & =\quad \text { the fraction of neutron events in the triples gate } f_{t} \approx\left(f_{d}\right)^{2}, \\
\tau & = & \text { the detector die-away time, } \\
P D & = & \text { the multiplicity circuit predelay, } \\
G & = & \text { the multiplicity electronics correlation event gate width, } \\
M & = & \text { the sample leakage multiplication, } \\
\alpha & = & \text { the ratio of }(\alpha, n) \text { neutrons to fission neutrons, } \\
v_{s i}= & \text { the } \mathrm{i}^{\text {th }} \text { moment of the spontaneous fission multiplicity distribution, and } \\
v_{i i}= & \text { the } \mathrm{i}^{\text {th }} \text { moment of the induced fission multiplicity distribution. }
\end{array}
$$

The S, D, and T rates are the quantities measured by the shift register and multiplicity circuits. The fraction of doubles $\left(f_{d}\right)$, and triples $\left(f_{t}\right)$ in the gate are typically measured using a ${ }^{252} \mathrm{Cf}$ source as $\alpha=0$ and $M=1$ for ${ }^{252} \mathrm{Cf}$. The detector efficiency can be easily measured using the ${ }^{252} \mathrm{Cf}$ source, but the energy spectra of the emitted neutrons are different from the plutonium resulting in a slightly different efficiency. Measurement of the detector efficiency with a plutonium sample requires that the sample be very well characterized. The moments of the spontaneous and induced fission distributions are given in Table VII. The detector dieaway $(\tau)$, predelay $(\mathrm{PD})$, and coincidence gate $(\mathrm{G})$ are a function of the detector and the resulting parameters are given in Table $\Pi$. 


\begin{tabular}{|c|c|c|c|c|c|c|c|}
\hline \hline \multicolumn{7}{|c|}{ Table VII. Measured Prompt Fission Moments ${ }^{7}$} \\
\hline Probability & ${ }^{238} \mathrm{Pu}$ & ${ }^{239} \mathrm{Pu}$ & ${ }^{240} \mathrm{Pu}$ & ${ }^{241} \mathrm{Pu}$ & ${ }^{242} \mathrm{Pu}$ & ${ }^{241} \mathrm{Am}$ & ${ }^{252} \mathrm{Cf}$ \\
\hline Distribution & & & & & & & \\
\hline$v_{\mathrm{s} 1}$ & 2.21 & 2.16 & 2.156 & 2.25 & 2.145 & 3.22 & 3.757 \\
\hline$v_{\mathrm{s} 2}$ & 3.957 & & 3.825 & & 3.794 & & 11.962 \\
\hline$v_{\mathrm{s} 3}$ & 5.596 & & 5.336 & & 5.317 & & 31.812 \\
\hline$v_{\mathrm{i} 1}$ & 2.9 & 2.879 & 2.8 & 2.931 & 2.81 & 3.09 & 4.06 \\
\hline$v_{\mathrm{i} 2}$ & & 6.773 & & 6.9946 & & & \\
\hline$v_{\mathrm{i} 3}$ & & 12.63 & & 13.2396 & & & \\
\hline
\end{tabular}
equations to

The standards used in the calibration were chosen such that $M=1$, reducing the

$$
\begin{aligned}
& S=F \varepsilon v_{\mathrm{s} 1}(1+\alpha), \\
& D=F \varepsilon^{2} \frac{f_{d}}{2} v_{s 2}, \text { and } \\
& T=F \varepsilon^{3} \frac{f_{t}}{6} v_{\mathrm{s} 3},
\end{aligned}
$$

which can be solved for the $\varepsilon, \alpha$, and $\mathrm{m}_{\mathrm{Pu}_{\mathrm{u} 40 e}}$. The fraction of coincident events in the gate parameters, $f_{d}$ and $f_{t}$, are calculated from the measurement of known plutonium samples.

The fractions were calculated using the FZC-158 plutonium sample in an empty drum and the volume-averaged point. The volume-averaged point occurs at the half height and twothirds radius of the 200-L drum. The isotopics of FZC-158 are given in Table VIII. Given $\alpha$ and $\mathrm{m}_{\mathrm{Pu240e}}$, we can calculate $\varepsilon, \mathrm{f}_{\mathrm{d}}$, and $\mathrm{f}_{\mathrm{t}}$ which are given by

$$
\begin{aligned}
& \varepsilon=S / F v_{s 1}(1+\alpha), \\
& f_{d}=2 \frac{D}{S} \frac{v_{s 1}}{v_{s 2}} \frac{(1+\alpha)}{\varepsilon}, \text { and } \\
& f_{t}=3 \frac{T}{D} \frac{v_{s 2}}{v_{s 3}} \frac{f_{d}}{\varepsilon} .
\end{aligned}
$$




\begin{tabular}{|c|c|c|}
\hline \multicolumn{3}{|c|}{ Table VIII. $\begin{array}{c}\text { FZC-158 Isotopics } \\
\text { and } \alpha\end{array}$} \\
\hline FZC-158 & $12 / 16 / 82$ & $03 / 07 / 97$ \\
\hline${ }^{\mathrm{Pu}_{2} 238}$ & 0.016 & 0.008 \\
\hline $\mathrm{Pu}_{239}$ & 0.955 & 0.969 \\
\hline${ }^{\mathrm{Pu}} 240$ & 93.76 & 94.381 \\
\hline${ }^{\mathrm{Pu}_{2} 241}$ & 0.699 & 0.007 \\
\hline${ }^{\mathrm{Pu}} 242$ & 4.56 & 4.637 \\
\hline${ }^{241} \mathrm{Am}$ & 0.001 & 0.624 \\
\hline${ }^{240} \mathrm{Pu}$-eff & 0.705 & 0.698 \\
\hline$\alpha$ & 0.130 & 0.145 \\
\hline
\end{tabular}

The resulting gate fractions are $f_{d}=0.666$ and $f_{t}=0.515$ (Note: this is not the usually assumed relationship of $f_{t}=f_{d}^{2}$ ). The efficiency was $\varepsilon=0.298$ with the polyethylene moderator of the interior of the sample cavity, and it changed to $\varepsilon=0.304$ when the polyethylene was moved behind the steel of the sample cavity. This differs slightly from the efficiency measured using the ${ }^{252} \mathrm{Cf}$ source because their fission neutron energy spectra differ. Upon moving the detector to the installation site, the resulting efficiencies were $30 \%$ for ${ }^{252} \mathrm{Cf}$ and $31 \%$ for plutonium.

The multiplicity approach given by Eq. (3) results in three equations and four unknowns $\left(\left\{\mathrm{m}_{\mathrm{P}_{\mathrm{u} 240 e}}, \varepsilon, \alpha, \mathrm{M}\right\}\right)$. Typically, the average efficiency of the detector is measured and becomes a fixed parameter for the point model to be soluble for $\left(\left\{\mathrm{m}_{\mathrm{Pu} 240}, \alpha, M\right\}\right)$. Since it is now assumed that the self-multiplication is given by $\mathbf{M}=1$, the efficiency becomes a free parameter and the solution set results in $\left(\left\{\mathrm{m}_{\mathrm{Pu} 240 \mathrm{e}}, \varepsilon, \alpha\right\}\right)$. The detection efficiency changes with respect to location and distribution of the sources within the drum. The efficiency is additionally altered by the addition of matrix materials which decrease the signal (hydrocarbons) or increase the signal (metals) as shown if Figs. 2, 3, and 4. A change in the detector's efficiency gives an indication of the matrix material within the drum.

The point model equations reduce to solve for $\varepsilon, \alpha$, and $\mathrm{m}_{\mathrm{Pu}_{240 \mathrm{e}}}$ are given by

$$
\begin{aligned}
\varepsilon & =3 \frac{T}{D} \frac{f_{d}}{f_{t}} \frac{v_{s 2}}{v_{s 3}} \\
\alpha & =\frac{3}{2} \frac{S T}{D^{2}} \frac{f_{d}^{2}}{f_{t}} \frac{v_{s 2}^{2}}{v_{s 1} v_{s 3}}-1, \text { and } \\
m_{P u 240} & =\frac{F}{479}=\left(\frac{1}{479}\right) \frac{2}{9} \frac{D^{3}}{T^{2}} \frac{f_{t}^{2}}{f_{d}^{3}} \frac{v_{s 3}^{2}}{v_{s 2}^{3}} .
\end{aligned}
$$


The uncertainty in the mass $\mathrm{m}_{\mathrm{Pu} 240}$ is given by

$$
\sigma_{m} / m_{P u 240 e}=\sqrt{\left(3 \frac{\sigma_{D}}{D}\right)^{2}+\left(2 \frac{\sigma_{T}}{T}\right)^{2}+2\left(\frac{3}{D}\right)\left(\frac{-2}{T}\right) \operatorname{cov}(D, T)} .
$$

In order to estimate the uncertainty without inverting the error matrices, the covariance terms are dropped to compare dependencies. Typically, the cross terms (covariance) has a $5 \%-40 \%$ effect. $^{8}$ Alternatively, if it is assumed that the correlation between the observable parameters are small then the uncertainty reduces to

$$
\sigma_{m} / m_{P u 240 e} \approx \sqrt{\left(3 \frac{\sigma_{D}}{D}\right)^{2}+\left(2 \frac{\sigma_{T}}{T}\right)^{2}} \propto \frac{2 \sigma_{T}}{T} .
$$

If the $\operatorname{cov}(D, T)>0$, then the error is reduced in the mass. As the full error propagation has not been implemented in software for this case, multiple runs for a given sample are used to estimate the uncertainty of the measurement.

\section{Bounded-Parameter Multiplicity Analysis}

BPMA uses the $\mathrm{D}$ and $\mathrm{T}$ rates to generate a passive $\mathrm{D}$ correction factor. A D correction factor is generated using the relationship between $\mathrm{D}$ and $\mathrm{m}_{\mathrm{Pu} 240 \mathrm{e}}$ and $\mathrm{T}$ and $\mathrm{m}_{\mathrm{Pu} 240 \mathrm{e}}$ as given in Table III and Fig. 5.

The passive $\mathrm{D}$ and $\mathrm{T}$ rates can be corrected for matrix effects and are related to mass by $\mathrm{a}$ "correction factor" and linear correspondence between a corrected rate to $\mathrm{m}_{\mathrm{Pu} 240 \mathrm{c}}$. The mass and rates are represented by

$$
\begin{aligned}
& \left.D_{c}=C F\right)_{D} D=a_{1} m_{P u 240 e} \text { and } \\
& \left.T_{c}=C F\right)_{T} T=a_{2} m_{P u 240 e},
\end{aligned}
$$

where $C F)_{D}$ and $\left.C F\right)_{T}$ are the matrix correction factors for D and $\mathrm{T}$, and $a_{1}$ and $a_{2}$ are the calibration slopes for the $\mathrm{D}$ and $\mathrm{T}$ related to mass of ${ }^{240} \mathrm{Pu}$. The above reduces to

$$
\frac{C F)_{D}}{C F)_{T}} \frac{D}{T}=\frac{a_{1}}{a_{2}}
$$

Measurements made to calibrate the $\mathrm{HENC}^{2}$ for typical matrix loadings of drums are given in Tables III and IX. One can generate the perturbation in the $\mathrm{D}\left(\Delta \mathrm{y}_{D}\right)$ and T $\left(\Delta y_{T}\right)$ as a function of AS perturbation ( $\delta$ ), as in Fig. 9. 
The form of the $\mathrm{D}$ and $\mathrm{T}$ correction factors are assumed to be

$$
\begin{aligned}
& C F)_{D}=1+\Delta y_{D}, \text { and } \\
& C F)_{T}=1+\Delta y_{T} .
\end{aligned}
$$

\begin{tabular}{|l|c|c|c|c|c|c|}
\hline \hline \multicolumn{1}{|c|}{ Table IX. } & \multicolumn{6}{c|}{ Perturbation of HENC Measured D and T } \\
\hline Sample & $\mathrm{D}$ & $\mathrm{T}$ & $\delta$ & $\mathrm{D} / \mathrm{T}$ & $\Delta \mathrm{y}_{\mathrm{d}}$ & $\Delta \mathrm{y}_{\mathrm{t}}$ \\
\hline Poly Tubes & 26.53 & 2.35 & 0.330 & 11.29 & 0.427 & 0.749 \\
\hline Paper I & 35.09 & 3.36 & 0.081 & 10.44 & 0.079 & 0.223 \\
\hline Paper II & 32.33 & 2.98 & 0.180 & 10.85 & 0.171 & 0.379 \\
\hline Paper III & 25.33 & 2.20 & 0.301 & 11.51 & 0.495 & 0.868 \\
\hline Wood & 31.75 & 2.81 & 0.167 & 11.30 & 0.193 & 0.463 \\
\hline
\end{tabular}

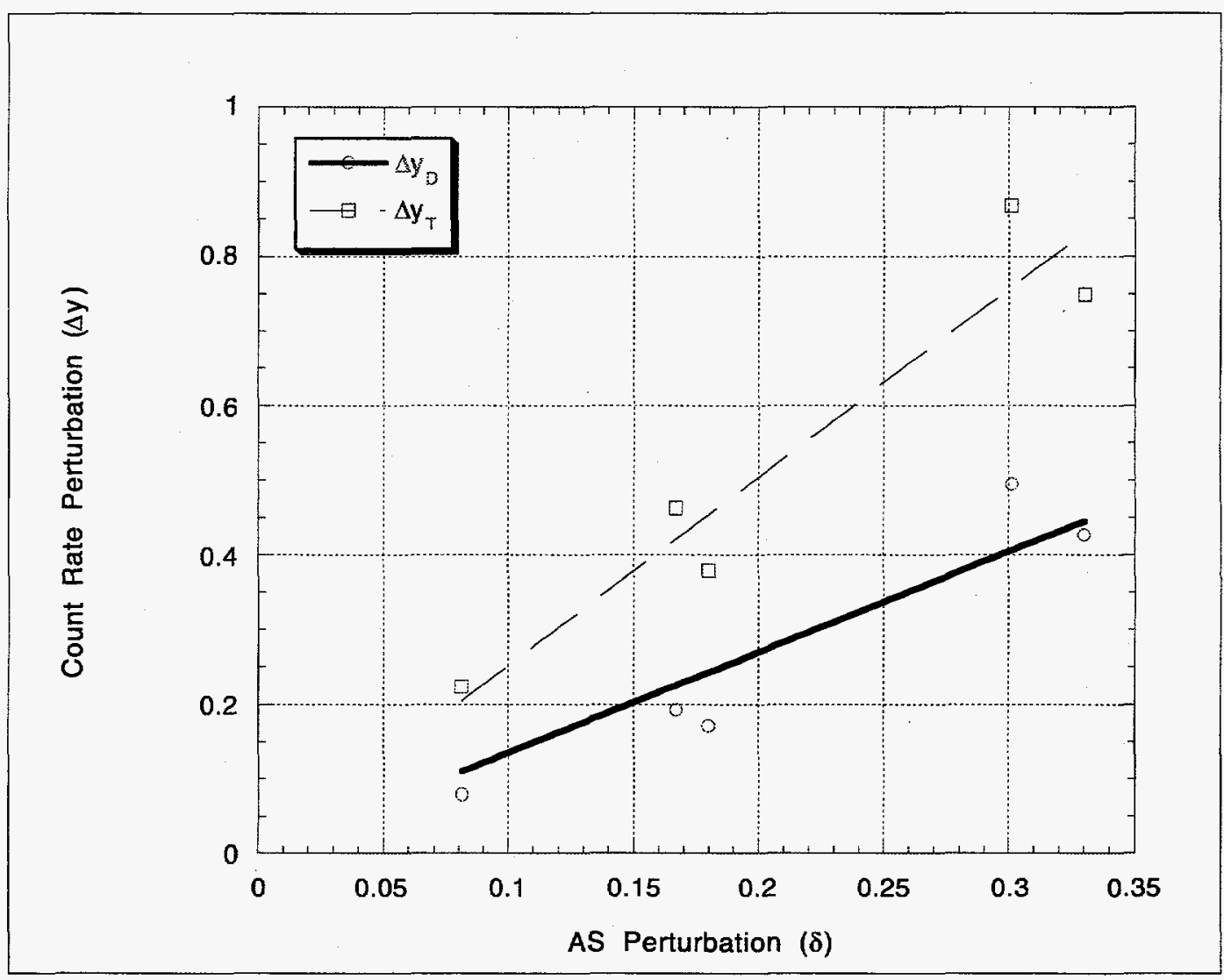

Fig. 9. Perturbation of $D\left(\Delta y_{D}\right)$ and $T\left(\Delta y_{T}\right)$ counting rate as a function of AS perturbation for the HENC.

A much steeper correction to the $\mathrm{T}$ rate is observed, which is a result of the $\mathrm{T}$ being a function of $\varepsilon^{3}$ and $D$ of $\varepsilon^{2}$. The relationship between the $D$ and $T$ perturbation is shown in Fig. 10. Although a higher polynomial may be used, the quality of the data does not warrant more than a linear relationship. 


$$
\Delta y_{T}=A \cdot \Delta y_{D}+B
$$

where $A$ and $B$ are the constants from the fit. The D perturbation $\left(\Delta y_{D}\right)$ can be expressed as a function of the $\mathrm{D}$ and $\mathrm{T}$ rates.

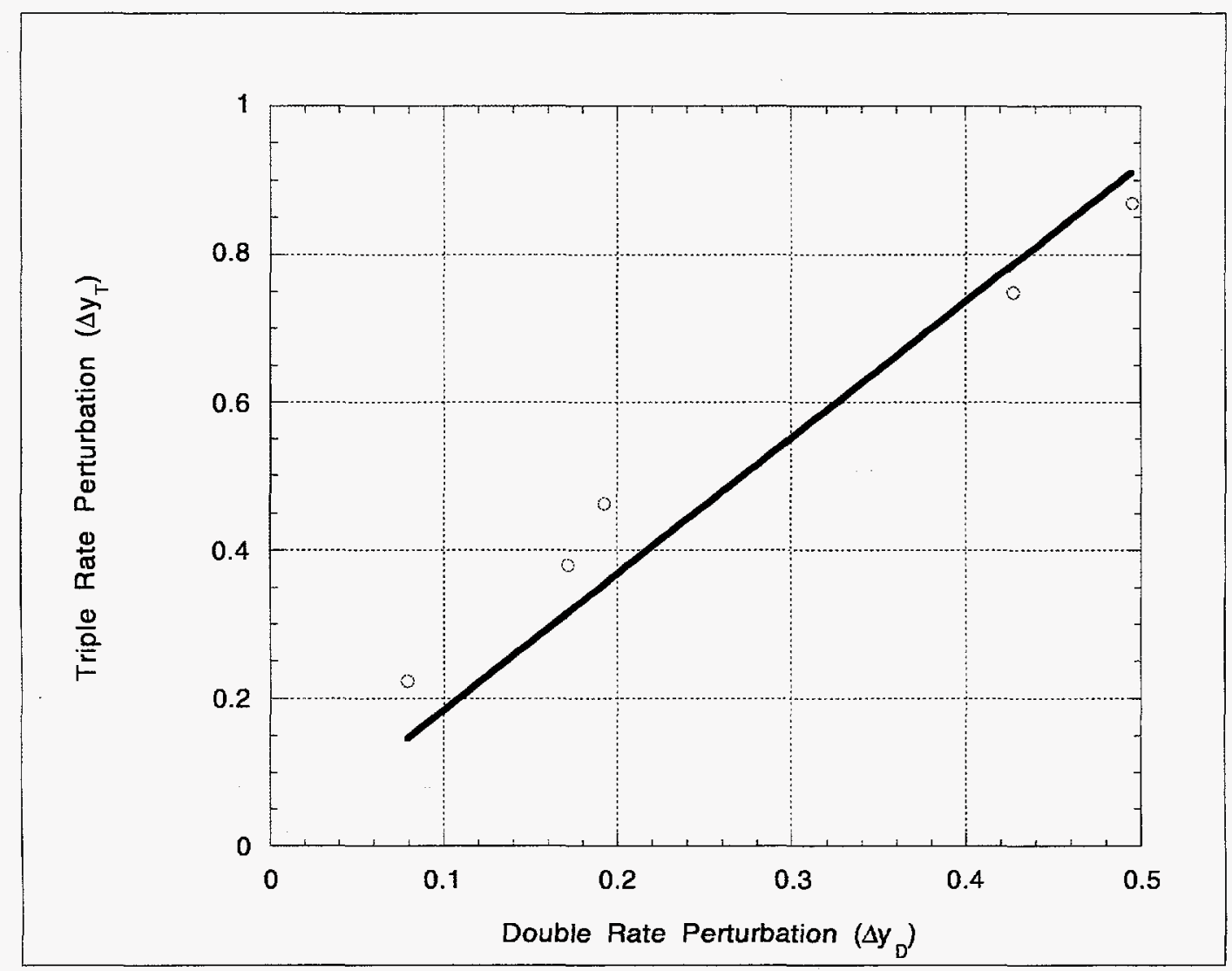

Fig. 10. Perturbation of $T$ rate to $D$ rate for HENC.

Using Eqs. (11-13), the D perturbation as a function of $\mathrm{D}$ and $\mathrm{T}$ is given by 


$$
\begin{aligned}
\frac{C F)_{D}}{C F)_{T}}= & \frac{a_{1}}{a_{2}} \frac{T}{D}, \\
\frac{1+\Delta y_{D}}{1+A \Delta y_{D}+B}= & \frac{a_{1}}{a_{2}} \frac{T}{D}, \text { and } \\
\Delta y_{D}= & \frac{\frac{a_{1}}{a_{2}}(1+B) T-D}{D-\frac{a_{1}}{a_{2}} A T} .
\end{aligned}
$$

For the HENC, ${ }^{2} a_{1}=53.8$ and $a_{2}=5.83$. If an empty drum is considered, then by definition $\Delta y_{D}=\Delta y_{T}=0$, which implies that $B=0$. If, however, Eq. (14) is set to zero as should be the case for an empty drum $\left(\Delta y_{D}=0\right)$, then we have

$$
B=\frac{D}{T} \frac{a_{2}}{a_{1}}-1=\left(\frac{37.87}{4.11}\right)\left(\frac{5.83}{58.3}\right)-1 \approx-0.0786 \pm 0.0920,
$$

which, within statistics is 0 . As shown in Fig. 10, the resulting fit for $\mathrm{B}=0$ is $\Delta \mathrm{y}_{\mathrm{D}}=1.8414 \Delta \mathrm{y}_{\mathrm{D}}$.

The BPMA D correction factor $C F)_{D}$ can be rewritten, resulting in the $\mathrm{m}_{\mathrm{Pu} u 40 \mathrm{e}}$ being given by

$$
m_{P u 240 e}=\frac{D_{C}}{a_{1}}=\frac{\left(1+\Delta y_{D}\right) D}{a_{1}}=\frac{(1-A) D T}{\left(a_{2} D-a_{1} A T\right)} .
$$

The uncertainty in the mass is given approximately by

$$
\begin{gathered}
\sigma_{m} / m_{P_{u} 240 e}=\left[\left(\frac{\partial m_{P_{u} 240 e}}{\partial D} \frac{\sigma_{D}}{m_{P u 240 e}}\right)^{2}+\left(\frac{\partial m_{P u 240 e}}{\partial T} \frac{\sigma_{T}}{m_{P u 240 e}}\right)^{2}+\right. \\
\left.2\left(\frac{\partial m_{P_{u} 240 e}}{\partial D} \frac{\sigma_{D}}{m_{P u 240 e}}\right)\left(\frac{\partial m_{P_{u} 240 e}}{\partial T} \frac{\sigma_{T}}{m_{P u 240 e}}\right) \operatorname{cov}(D, T)\right]^{1 / 2} .
\end{gathered}
$$

Once again, the $\operatorname{cov}(D, T)$ is dropped for comparison, resulting in

$$
\begin{aligned}
\sigma_{m} / m_{P_{u} 240 e} & \approx \sqrt{\left[\left(\frac{-a_{1} A T}{a_{2} D-a_{1} A T}\right) \frac{\sigma_{D}}{D}\right]^{2}+\left[\left(\frac{a_{2} D}{a_{2} D-a_{1} A T}\right) \frac{\sigma_{T}}{T}\right]^{2}}, \\
& =\frac{1}{\left|a_{2} D-a_{1} A T\right|} \sqrt{\left[\left(a_{1} A T\right) \frac{\sigma_{D}}{D}\right]^{2}+\left[\left(a_{2} D\right) \frac{\sigma_{T}}{T}\right]^{2}} .
\end{aligned}
$$


The uncertainty in the mass calculated by the BPMA method is less than that of the multiplicity analysis as the $\mathrm{D}$ perturbation is a small fraction of the correction factor.

\section{Comparison of Multiplicity and BPMA Uncertainties}

Consider two samples with masses of $69 \mathrm{~g}$ and $95 \mathrm{~g}$ of plutonium. The $69 \mathrm{~g}$ and $95-\mathrm{g}$ cases have a $\mathrm{D}=330.6$ and $\mathrm{T}=34.43$, and $\mathrm{D}=206.3 \mathrm{~T}=20.59$, respectively. Then using Eqs. (9) and (18) as shown in Fig. 11 for a fixed uncertainty of $1 \%$ in the $\mathrm{D}$ rate (i.e., $\sigma_{\mathrm{D} / \mathrm{D}}=$ 0.01 ), the multiplicity error scales as $\frac{2 \sigma_{T}}{T}$. The BPMA results in a lower uncertainty in the mass and scales as $\frac{3}{2} \frac{\sigma_{T}}{T}$.

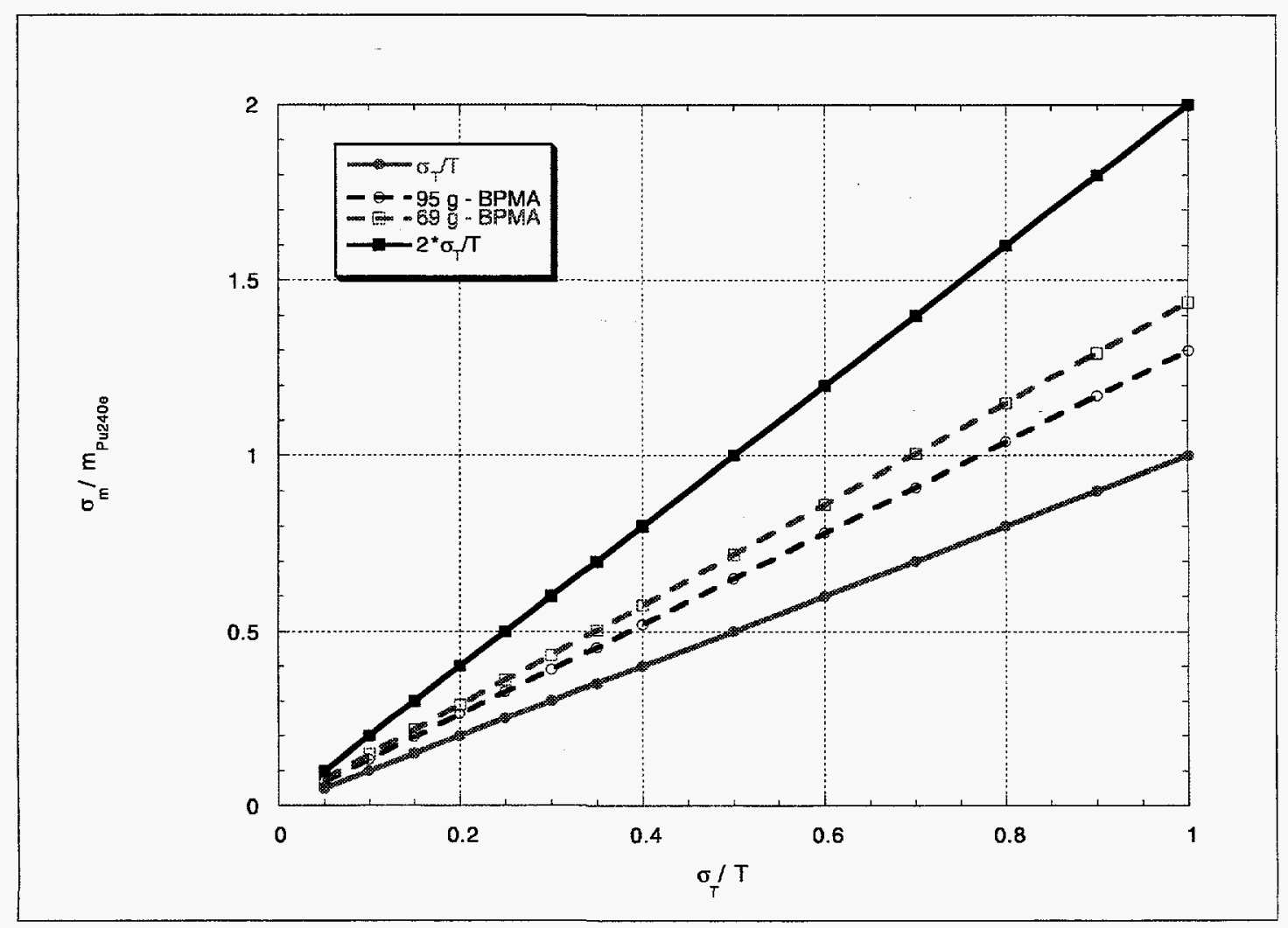

Fig. 11. Comparison of uncertainties in the mass $\left(\sigma_{m} / m\right)$ for a 69-g and 95-g sample as a function of the uncertainty in the $T$ counting rate $\left(\sigma_{T} / T\right)$. The multiplicity result matches $2 \sigma_{T} / T$. 


\section{RESULTS}

The three analysis methods (AS, multiplicity, BPMA) are examined using the calibration data set. The results of the analyses are given in Table $\mathrm{X}$ and displayed in Fig. 12. The AS method does best over the entire range as expected. The multiplicity analysis does poorly for the iron metal and sand cases and overcorrects for the lighter loadings of paper and wood. The attenuation of the matrix shows up in the change in detector efficiency as well as in the mass. The BPMA seems to fluctuate from the AS result in the same direction as the multiplicity analysis, but the fluctuations are damped due to the lesser dependence on the $\mathrm{T}$ rate.

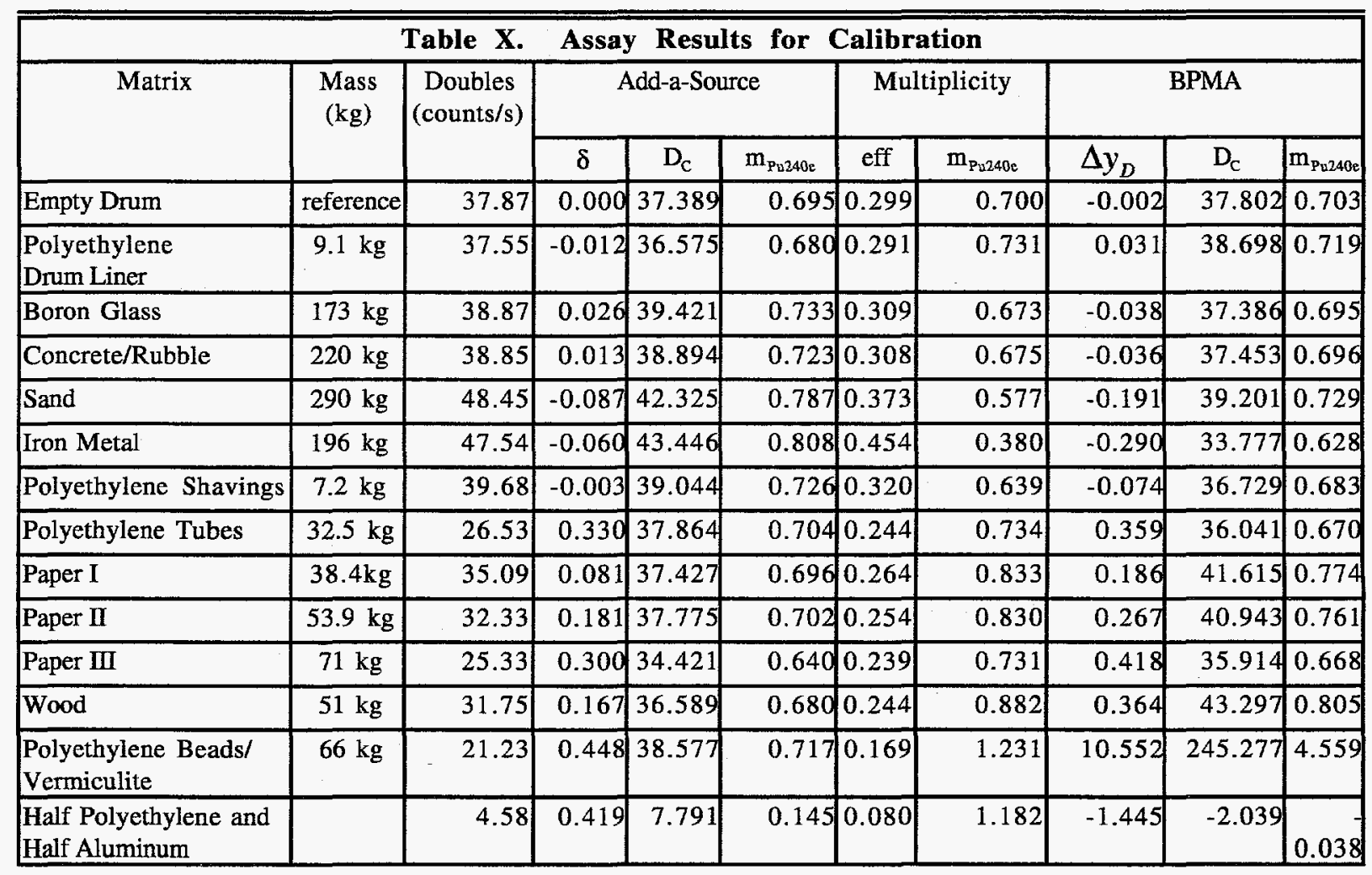




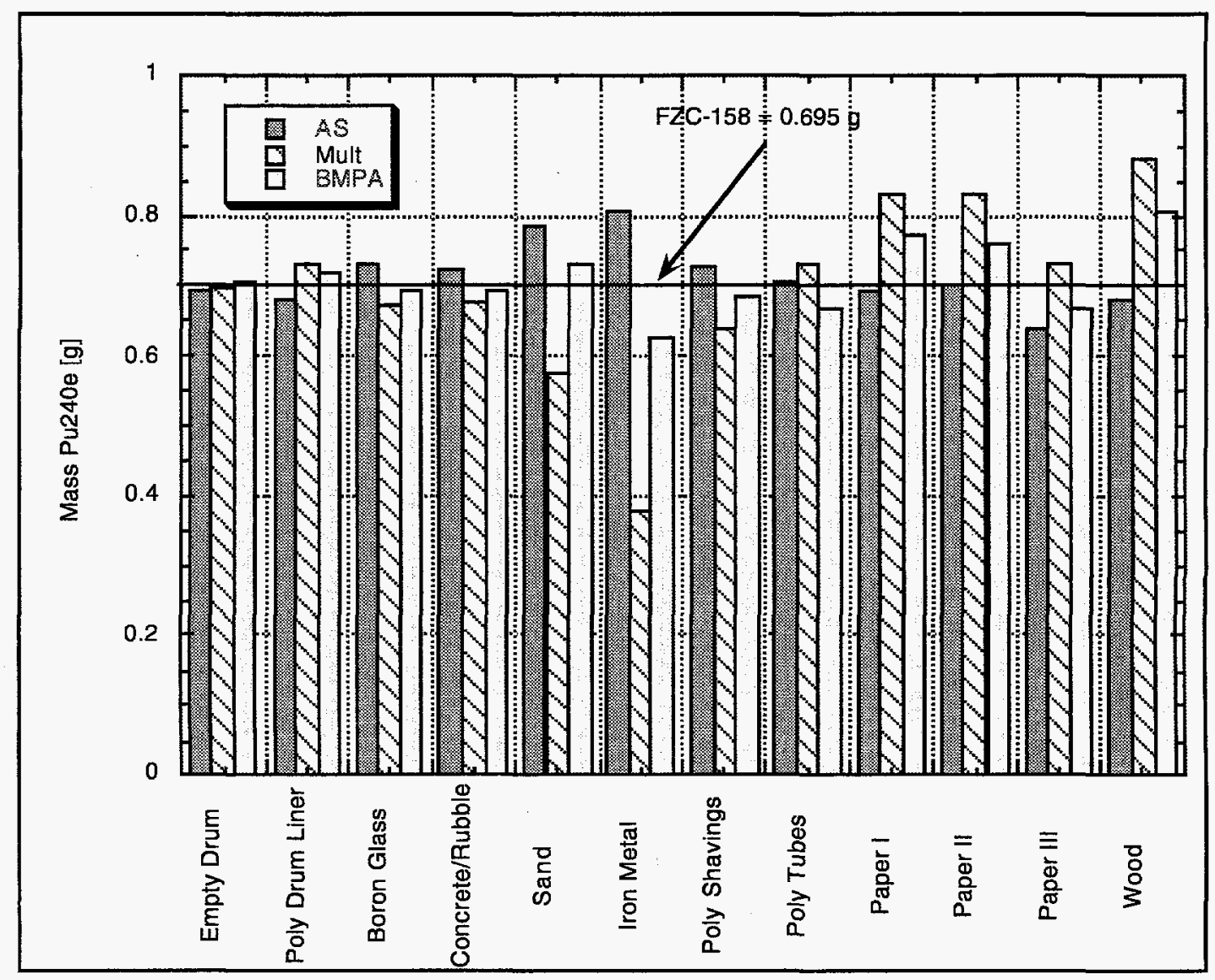

Fig. 12. Comparison of results from AS, multiplicity analysis, and BPMA.

\section{A. PDP Cycle 2}

The HENC with the Los Alamos NCC software was tested on two PDP drums in the PDP cycle 2. ${ }^{9}$ The passive calibration, AS calibration, and deadtime parameters used for the cycle are given in Figs. 5 and 6, and Table II, respectively. Each of the PDP drums were measured in passive mode for $10 \mathrm{~min}$ followed by a 3-min run of the ${ }^{252} \mathrm{Cf} \mathrm{AS}$ for matrix corrections. Six sets of data were taken for each barrel. The data were taken in 10-s time intervals to minimize the effects of cosmic-ray spallation events ${ }^{2}$ in the background. The higher multiplicities are typical of cosmic-ray events and are rejected by the quality control tests in the software. Table XI lists the data for both of the drums measured, PDP-002 and PDP003 , as well as the AS analysis performed by the code. 


\begin{tabular}{|c|c|c|c|c|c|c|}
\hline \multicolumn{7}{|c|}{ Data with AS Re } \\
\hline \multirow[b]{2}{*}{ PDP-002 } & \multirow{2}{*}{$\begin{array}{c}\text { Singles } \\
\text { (counts/s) }\end{array}$} & \multirow{2}{*}{$\begin{array}{c}\text { Doubles } \\
\text { (counts/s) }\end{array}$} & \multirow{2}{*}{$\begin{array}{c}\text { Triples } \\
\text { (counts/s) }\end{array}$} & \multicolumn{3}{|l|}{ Add-a-Source } \\
\hline & & & & $\mathrm{CF}$ & $\mathrm{m}_{\mathrm{Pu} 240 \mathrm{c}}$ & $\overline{m_{\mathrm{Pu}}}$ \\
\hline 1 & 46.33 & 2.511 & 0.448 & 1.409 & 0.066 & 1.083 \\
\hline 2 & 47.14 & 2.315 & 0.267 & 1.397 & 0.060 & 0.990 \\
\hline 3 & 45.95 & 1.961 & 0.110 & 1.340 & 0.049 & 0.804 \\
\hline 4 & 45.29 & 2.015 & 0.331 & 1.407 & 0.053 & 0.868 \\
\hline 5 & 45.61 & 2.117 & 0.183 & 1.413 & 0.056 & 0.916 \\
\hline 6 & 45.25 & 1.869 & 0.091 & 1.358 & 0.047 & 0.777 \\
\hline Mean & 45.93 & 2.131 & 0.238 & 1.387 & 0.055 & 0.906 \\
\hline Std. Dev. & 0.72 & 0.241 & 0.138 & 0.031 & 0.007 & 0.116 \\
\hline Std. Dev. [\%] & 1.57 & 11.289 & 57.716 & 2.212 & 12.765 & 12.765 \\
\hline \multirow[b]{2}{*}{ PDP-003 } & \multirow{2}{*}{$\begin{array}{c}\text { Singles } \\
\text { (counts/s) }\end{array}$} & \multirow{2}{*}{$\begin{array}{l}\text { Doubles } \\
\text { (counts/s) }\end{array}$} & \multirow{2}{*}{$\begin{array}{c}\text { Triples } \\
\text { (counts } / s)\end{array}$} & \multicolumn{3}{|l|}{ Add-a-Source } \\
\hline & & & & $\mathrm{CF}$ & $\mathrm{m}_{\mathrm{Pu} 240 \mathrm{e}}$ & $\mathrm{m}_{\mathrm{Pu}}$ \\
\hline 1 & 446.6 & 23.87 & 1.984 & 1.232 & 0.547 & 9.002 \\
\hline 2 & 445.6 & 24.55 & 2.386 & 1.226 & 0.559 & 9.214 \\
\hline 3 & 446.2 & 24.01 & 2.010 & 1.224 & 0.546 & 8.996 \\
\hline 4 & 445.7 & 23.78 & 2.301 & 1.199 & 0.530 & 8.728 \\
\hline 5 & 445.7 & 24.30 & 2.676 & 1.236 & 0.558 & 9.194 \\
\hline 6 & 444.7 & 23.67 & 2.018 & 1.223 & 0.538 & 8.862 \\
\hline Mean & 445.8 & 24.03 & 2.229 & 1.223 & 0.546 & 8.999 \\
\hline Std. Dev. & 0.64 & 0.34 & 0.276 & 0.013 & 0.011 & 0.188 \\
\hline Std. Dev. [\%] & 0.14 & 1.39 & 12.402 & 1.057 & 2.087 & 2.087 \\
\hline
\end{tabular}

The isotopic composition of the samples were assumed to be $\sim 6 \%{ }^{240} \mathrm{Pu}$, and the passive calibration constant of 53.8 counts/s•g - Pu240e was used for all measurements. The HENC measurement resulted in

and

$$
0.906 \pm 0.047 \mathrm{~g} \text { plutonium for PDP-002 }
$$

$$
9.00 \pm 0.077 \mathrm{~g} \text { plutonium for PDP-003, }
$$

where the uncertainties are the one standard deviation values based solely on counting statistics. The uncertainty in the matrix correction was $\sim 5 \%{ }^{9}$

An alternative way to calculate the uncertainty, which would include systematic as well as statistical uncertainties, is to calculate the mean and standard deviation of the six measurements. In this case, the HENC reports

and

$$
0.906 \pm 0.116 \mathrm{~g} \text { plutonium for PDP-002 }
$$




$$
9.00 \pm 0.19 \mathrm{~g} \text { plutonium for PDP-003. }
$$

This method allows for the intercomparison with the two other methods. Table XII contains the multiplicity and BPMA results. The results of AS, multiplicity analysis, and BPMA are shown in Fig. 13.

\begin{tabular}{|c|c|c|c|c|c|c|c|}
\hline \multirow[b]{3}{*}{ PDP-002 } & \multirow{2}{*}{\multicolumn{3}{|c|}{$\begin{array}{l}\text { Table XII. } \\
\text { Multiplicity }\end{array}$}} & PMA Resi & Its for & PDP Cycle & 2 \\
\hline & & & & \multicolumn{4}{|c|}{ BPMA } \\
\hline & eff & $\mathrm{m}_{\mathrm{Pu} 240 \mathrm{e}}$ & $\mathrm{m}_{\mathrm{Pu}_{\mathrm{u}}}$ & $\Delta \mathrm{y}_{\mathrm{D}}$ & $\overline{C F}$ & $\mathrm{~m}_{\mathrm{Pu} 240 \mathrm{c}}$ & $\mathrm{m}_{\mathrm{Pu}}$ \\
\hline 1 & 0.492 & 0.0171631 & 0.283 & -0.318 & 0.682 & 0.032 & 0.524 \\
\hline 2 & 0.318 & 0.0378653 & 0.624 & -0.067 & 0.933 & 0.040 & 0.661 \\
\hline 3 & 0.155 & 0.1355995 & 2.233 & -10.303 & -9.303 & -0.339 & -5.585 \\
\hline 4 & 0.453 & 0.0162472 & 0.268 & -0.288 & 0.712 & 0.027 & 0.439 \\
\hline 5 & 0.238 & 0.0616412 & 1.015 & 0.431 & 1.431 & 0.056 & 0.928 \\
\hline 6 & 0.134 & 0.1715362 & 2.825 & -3.190 & -2.190 & -0.076 & -1.253 \\
\hline Mean & 0.298 & 0.073 & 1.208 & -2.289 & -1.289 & -0.043 & -0.714 \\
\hline Std. Dev. & 0.150 & 0.065 & 1.076 & & & 0.152 & 2.509 \\
\hline \multirow[t]{3}{*}{$\begin{array}{l}\text { Std. Dev. } \\
{[\%]}\end{array}$} & 50.372 & 89.054 & 89.054 & & & -351.208 & -351.208 \\
\hline & & & & & & & \\
\hline & \multicolumn{3}{|l|}{ Multiplicity } & \multicolumn{4}{|l|}{ BPMA } \\
\hline PDP-003 & eff & $\mathrm{m}_{\mathrm{Pu} 240 \mathrm{e}}$ & $\mathrm{m}_{\mathrm{Pu}_{\mathrm{u}}}$ & $\Delta \mathrm{y}_{\mathrm{D}}$ & $\mathrm{CF}$ & $\mathrm{m}_{\mathrm{Pu240e}}$ & $\mathrm{m}_{\mathrm{Pu}_{\mathrm{u}}}$ \\
\hline 1 & 0.229 & 0.7517693 & 12.381 & 0.565 & 1.565 & 0.694 & 11.435 \\
\hline 2 & 0.268 & 0.5654891 & 9.313 & 0.158 & 1.158 & 0.529 & 8.705 \\
\hline 3 & 0.231 & 0.7454097 & 12.276 & 0.538 & 1.538 & 0.687 & 11.306 \\
\hline 4 & 0.267 & 0.5526026 & 9.101 & 0.166 & 1.166 & 0.515 & 8.489 \\
\hline 5 & 0.303 & 0.4359706 & 7.180 & -0.019 & 0.981 & 0.443 & 7.300 \\
\hline 6 & 0.235 & 0.7085379 & 11.669 & 0.475 & 1.475 & 0.649 & 10.689 \\
\hline Mean & 0.255 & 0.627 & 10.320 & 0.314 & 1.314 & 0.586 & 9.654 \\
\hline Std. Dev. & 0.029 & 0.128 & 2.110 & & & 0.1043766 & 1.719 \\
\hline $\begin{array}{l}\text { Std. Dev. } \\
{[\%]}\end{array}$ & 11.501 & 20.443 & 20.443 & & & 17.805631 & 17.806 \\
\hline
\end{tabular}

Both the multiplicity and BPMA do poorly for the low-mass relatively high-attenuating $(\delta \approx 0.4)$ PDP-002 case. This is directly related to large fluctuations in the T count rate, on which, the AS does not rely. Note that the results from each method are consistent for PDP002 and PDP-003. The large fluctuations in the $\mathrm{T}$ rate leads to a large D/T ratio, which is outside the range of the BPMA. 


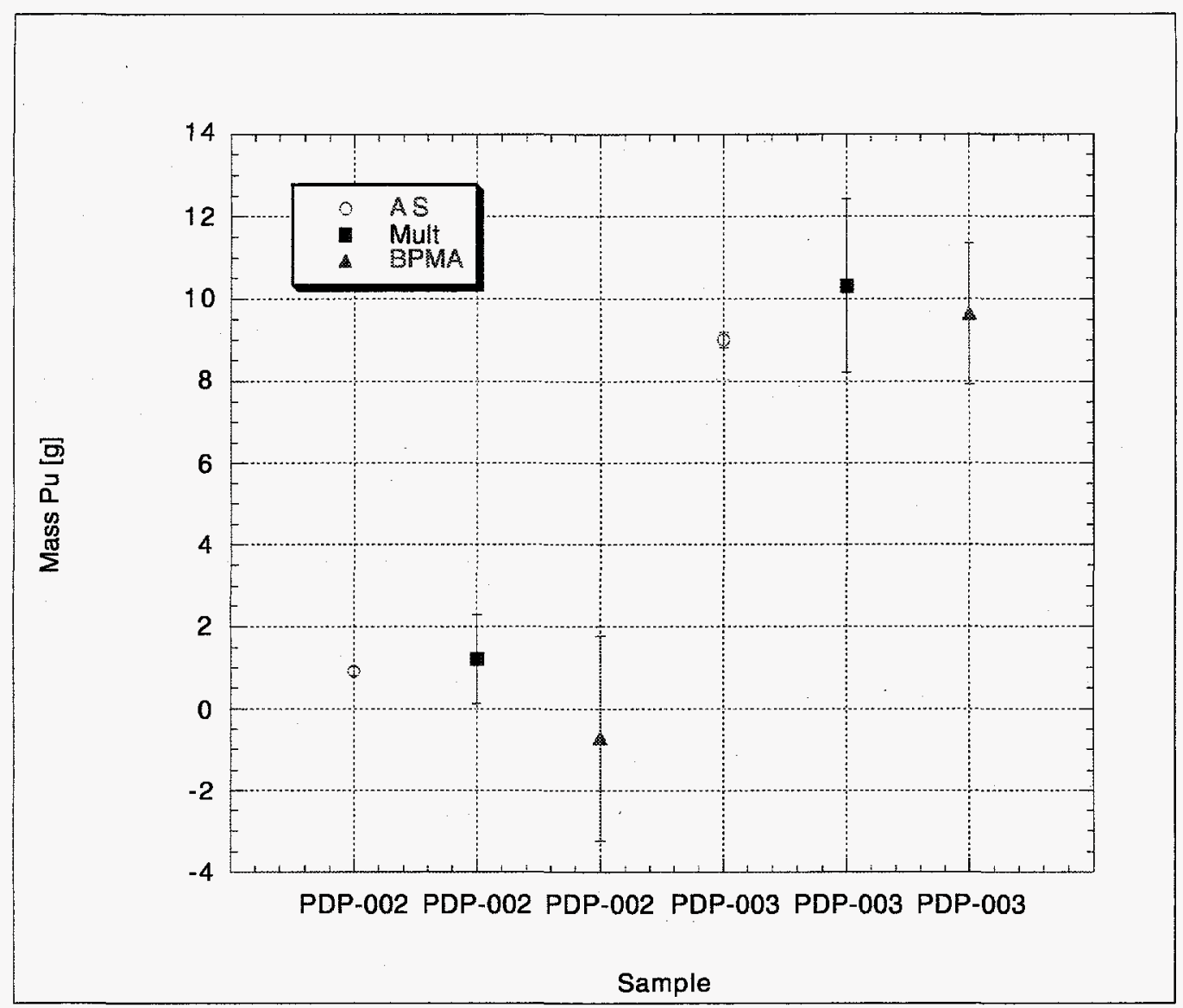

Fig. 13. Comparison of HENC results using the AS, multiplicity analysis, and BPMA for PDP cycle 2.

The multiplicity and BPMA method perform better for the PDP-003 drum $(\delta \approx 0.2)$ which has a stronger neutron source and a lower degree of fluctuations in the measured $\mathrm{T}$ rate. The uncertainty in the BPMA method is less than the multiplicity method as expected from the discussion in Section II.

\section{B . PDP Cycle 3}

Measurements for the PDP cycle 3 followed the same procedure as cycle 2 for the drums PDP-004 and PDP-003. The resulting data are given in Table XIII. The HENC with AS reports

and

$$
95.11 \pm 1.19 \mathrm{~g} \text { plutonium for PDP-004 }
$$

$69.32 \pm 0.72 \mathrm{~g}$ plutonium for PDP-003. 
Both drums were fairly nonperturbative for neutrons $(\delta \approx 0.1-0.2)$.

\begin{tabular}{|c|c|c|c|c|c|c|}
\hline \multirow[b]{3}{*}{ PDP-004 } & \multirow{3}{*}{\begin{tabular}{|c|} 
ble XIII. \\
$\begin{array}{c}\text { Singles } \\
(\text { counts/s) }\end{array}$
\end{tabular}} & \multirow{3}{*}{$\begin{array}{c}\text { HENC PD } \\
\begin{array}{c}\text { Doubles } \\
\text { (counts/s) }\end{array}\end{array}$} & \multirow{3}{*}{$\frac{\text { Cycle } 3}{\text { Triples }}$} & \multirow{3}{*}{$\begin{array}{l}\text { Data with A } \\
\text { Add-a-Source } \\
\text { CF } \\
\end{array}$} & Results & \multirow[b]{3}{*}{$\mathrm{m}_{\mathrm{Pu}}$} \\
\hline & & & & & & \\
\hline & & & & & $\mathrm{m}_{\mathrm{Pu} 240 \mathrm{e}}$ & \\
\hline 1 & 5640 & 333.7 & 35.91 & 1.057 & 6.156 & 95.11 \\
\hline & 5640 & 333.8 & 37.99 & 1.072 & 6.245 & 96.49 \\
\hline 3 & 5640 & 332.0 & 36.56 & 1.077 & 6.240 & 96.42 \\
\hline 4 & 5645 & 330.1 & 32.74 & 1.065 & 6.135 & 94.80 \\
\hline 5 & 5639 & 328.3 & 29.03 & 1.066 & 6.108 & 94.37 \\
\hline 6 & 5639 & 325.7 & 34.33 & 1.064 & 6.048 & 93.45 \\
\hline Mean & 5641 & 330.6 & 34.43 & 6.401 & 6.155 & 95.11 \\
\hline Std. Dev. & 2 & 3.2 & 3.21 & 0.007 & 0.077 & 1.19 \\
\hline $\begin{array}{l}\text { Std. Dev. } \\
{[\%]}\end{array}$ & 0.04 & 0.969 & 9.316 & 0.108 & 1.247 & 1.247 \\
\hline & & & & & & \\
\hline \multirow[b]{2}{*}{ PDP-003 } & Singles & Doubles & Triples & \multicolumn{3}{|l|}{ Add-a-Source } \\
\hline & (counts/s) & (counts/s) & (counts/s) & $\mathrm{CF}$ & $\mathrm{m}_{\mathrm{Pu} 240 \mathrm{c}}$ & $\mathrm{m}_{\mathrm{Pu}}$ \\
\hline 1 & 3966 & 205.0 & 21.05 & 1.243 & 4.447 & 68.71 \\
\hline 2 & 3965 & 209.0 & 20.95 & 1.238 & 4.516 & 69.77 \\
\hline 3 & 3970 & 207.8 & 19.78 & 1.248 & 4.526 & 69.93 \\
\hline 4 & 3974 & 205.4 & 21.53 & 1.237 & 4.434 & 68.51 \\
\hline 5 & 3967 & 206.6 & 20.05 & 1.260 & 4.543 & 70.20 \\
\hline 6 & 3971 & 204.0 & 20.20 & 1.251 & 4.454 & 68.82 \\
\hline Mean & 3969 & 206.3 & 20.59 & 7.477 & 4.487 & 69.32 \\
\hline Std. Dev. & 3 & 1.9 & 0.68 & 0.009 & 0.047 & 0.72 \\
\hline $\begin{array}{l}\text { Std. Dev. } \\
{[\%]}\end{array}$ & 0.09 & 0.90 & 3.311 & 0.116 & 1.043 & 1.043 \\
\hline
\end{tabular}

The multiplicity and BPMA are given in Table XIV with a comparison of the three methods in Fig. 14. The BPMA and AS do not overlap within one standard deviation for the PDP-003, the multiplicity analysis easily overlaps with both. This is indicative of the refinement needed in the data, as shown in Fig. 10, for calculating the BPMA equations . 


\begin{tabular}{|c|c|c|c|c|c|c|c|}
\hline \multirow{2}{*}{\multicolumn{4}{|c|}{\begin{tabular}{r|l}
\multicolumn{1}{c}{ Table } \\
\end{tabular}}} & MA Re & ts for & DP Cycl & e 3 \\
\hline & & & & \multicolumn{4}{|l|}{ BPMA } \\
\hline PDP-004 & eff & $\mathrm{m}_{\mathrm{Pu} 240 \mathrm{c}}$ & $m_{P_{u}}$ & $\Delta y$ & $\mathrm{CF}$ & $\mathrm{m}_{\mathrm{Pu} 240 \mathrm{e}}$ & $\mathrm{m}_{\mathrm{Pu}}$ \\
\hline 1 & 0.297 & 6.270 & 96.87 & 0.008 & 1.008 & 5.873 & 90.74 \\
\hline 2 & 0.314 & 5.607 & 86.63 & -0.054 & 0.946 & 5.512 & 85.17 \\
\hline 3 & 0.303 & 5.957 & 92.04 & -0.019 & 0.981 & 5.686 & 87.86 \\
\hline 4 & 0.273 & 7.301 & 112.81 & 0.124 & 1.124 & 6.473 & 100.02 \\
\hline 5 & 0.244 & 9.135 & 141.15 & 0.366 & 1.366 & 7.827 & 120.94 \\
\hline 6 & 0.290 & 6.378 & 98.55 & 0.035 & 1.035 & 5.880 & 90.86 \\
\hline Mean & 0.287 & 6.775 & 104.68 & 0.077 & 1.077 & 6.209 & 95.93 \\
\hline Std. Dev. & 0.025 & 1.288 & 19.90 & & & 0.857 & 13.23 \\
\hline \multirow[t]{2}{*}{$\begin{array}{l}\text { Std. Dev. } \\
{[\%]}\end{array}$} & 8.747 & 19.012 & 19.012 & & & 13.796 & 13.796 \\
\hline & & & & & & & \\
\hline \multirow[b]{2}{*}{ PDP-003 } & \multicolumn{3}{|l|}{ Multiplicity } & \multicolumn{4}{|l|}{ BPMA } \\
\hline & eff & $\mathrm{m}_{\mathrm{Pu} 240 \mathrm{e}}$ & $\mathrm{m}_{\mathrm{Pu}}$ & $\Delta y$ & $\mathrm{CF}$ & $\mathrm{m}_{\mathrm{Pu} 240 e}$ & $\mathrm{~m}_{\mathrm{Pu}}$ \\
\hline 1 & 0.283 & 4.230 & 65.36 & 0.070 & 1.070 & 3.829 & 59.17 \\
\hline 2 & 0.276 & 4.526 & 69.93 & 0.107 & 1.107 & 4.036 & 62.37 \\
\hline 3 & 0.262 & 4.990 & 77.10 & 0.197 & 1.197 & 4.341 & 67.07 \\
\hline 4 & 0.289 & 4.067 & 62.85 & 0.042 & 1.042 & 3.735 & 57.71 \\
\hline 5 & 0.267 & 4.773 & 73.75 & 0.161 & 1.161 & 4.186 & 64.67 \\
\hline 6 & 0.273 & 4.527 & 69.95 & 0.126 & 1.126 & 4.010 & 61.96 \\
\hline Mean & 0.275 & 4.519 & 69.82 & 0.117 & 1.117 & 4.023 & 62.16 \\
\hline Std. Dev. & 0.010 & 0.339 & 5.23 & & & 0.223 & 3.44 \\
\hline $\begin{array}{l}\text { Std. Dev. } \\
{[\%]}\end{array}$ & 3.560 & 7.495 & 7.50 & & & 5.539 & 5.539 \\
\hline
\end{tabular}




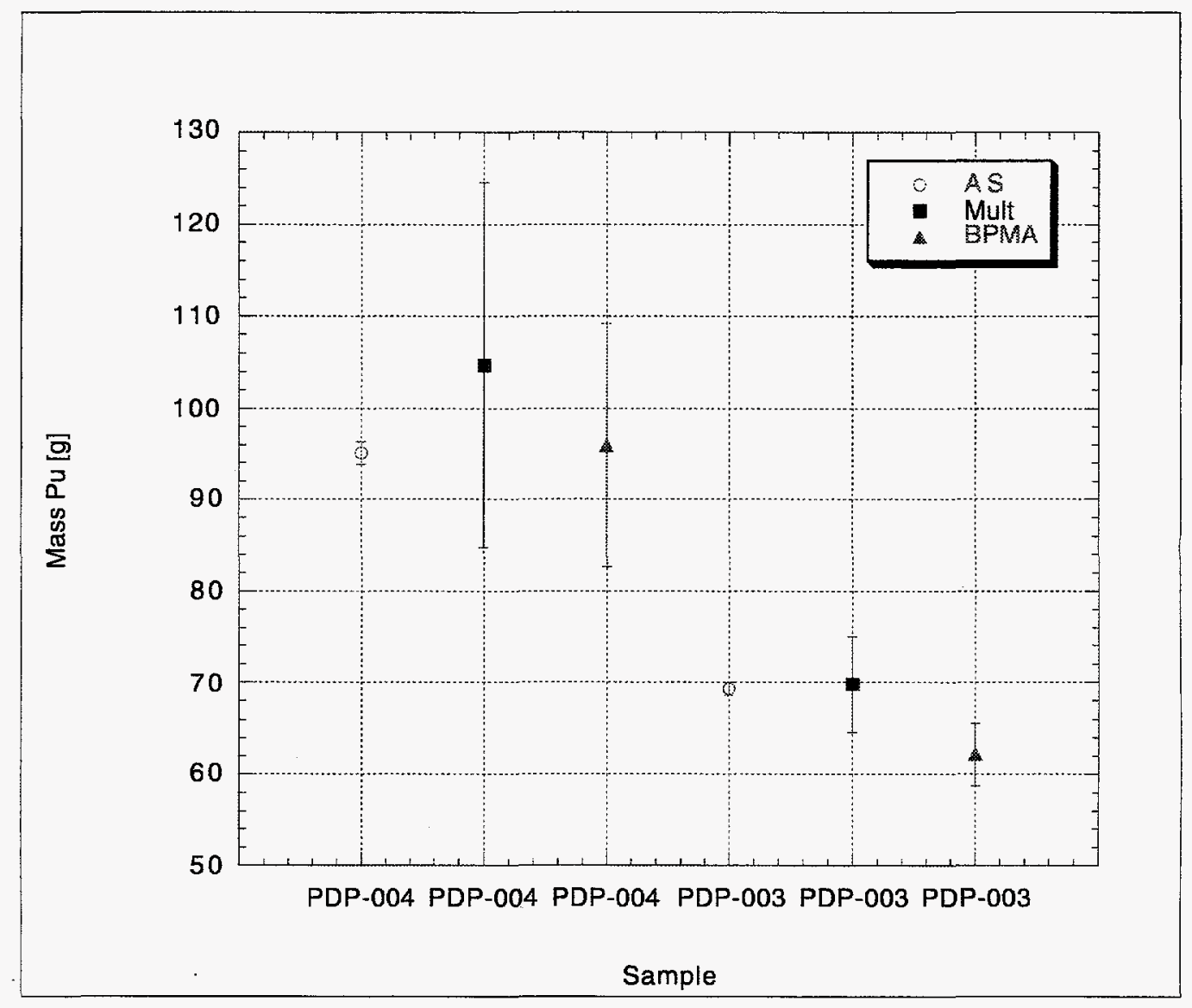

Fig. 14. Comparison of $H E N C$ results using the AS, muliplicity analysis, and BPMA for PDP cycle 3.

\section{REGIONS OF APPLICABILITY}

Each of the three assay techniques (AS, multiplicity analysis, BPMA) have various regions of applicability, but are achievable with one instrument, such as the HENC. The AS method relies only on measuring the D rate and the AS perturbation measurement. The AS technique covers a wide range of matrix drums, but becomes unreliable for drums with a high hydrogen content and segregated plutonium. However, "typical" waste matrix doses have a high hydrogen mass fraction. The HENC can achieve 1\% statistical uncertainty in the D count rate for a 10 -g plutonium sample with a 10 -min passive run and $3-\mathrm{min}^{252} \mathrm{Cf}$ AS run. The lower detectability limit depends on the matrix and background rate. The detectability limit at Los Alamos is $20 \mathrm{mg}{ }^{240} \mathrm{Pu}$ and, at sea level, drops to less than $10 \mathrm{mg}{ }^{240} \mathrm{Pu}$.

The multiplicity assay does not require the construction of a wide range of matrix drums to calibrate the system. This method requires accurate determination of the fraction in the gates of $\mathrm{D}$ and $\mathrm{T}$. It requires reasonable statistics in the $\mathrm{T}$ count rate for low uncertainties in the measurement. This becomes a problem of highly attenuating matrices (i.e, high hydrogen content) or low sample masses, thus resulting in longer and possibly unreasonable run times 
for assay. A $10-\mathrm{g}$ sample resulted in a measurement with a multiplicity precision of $20 \%$ for a 10-min measurement.

The BMPA reduces the effects of poor counting statistics found in the multiplicity assay and results in lower uncertainties than multiplicity. It does not, however, approach the small statistical uncertainty levels of the AS technique.

None of the three techniques are very accurate for the extremely attenuating cases and small source strengths. An additional constraint on the system's ability is the construction of a drum similar to those measured for proper characterization of background effects of the matrix for samples with plutonium loadings near the detectability limit.

\section{DIVERSION SCENARIO}

A safeguards concern is the possibility of a diversion of plutonium from dismantlement or decommissioning processes. For example, an insider purposely shields the material within a barrel. The supposition is that waste drums are from high-plutonium areas and are modified to pass the required tests to be certified as waste to be shipped to a less-guarded facility. The signal reduction may be achieved by local shielding. The source in question is placed within a moderator to reduce the S or D rates. The AS technique, as implemented in the HENC with three positions, allows for indication of stratification layers or local shielding. A local shield would be indicated by a larger absorption of neutrons at a given level. Presence would be shown depending on source location compared to shield.

The first series of tests, reported in Table XV, investigate the case of a plutonium source shielded by polyethylene $\left(\mathrm{CH}_{2}\right)$. Single runs were recorded. The source was not at the volume-averaged point (half height and two-thirds radius), so the resulting data for the empty drum may be higher or lower depending on position. The FZC-158 plutonium source, which is $\sim 0.70 \mathrm{~g}{ }^{240} \mathrm{Pu}\left(\sim 10 \mathrm{~g}\right.$ plutonium), was placed inside of a $\mathrm{CH}_{2}$ cylinder, and additional masses of polyethylene (poly) bead and borated poly blocks were added.

The AS method produced no correction for the lone $\mathrm{CH}_{2}$ cylindrical shield and consistently underestimates the plutonium mass for all cases. The multiplicity analysis and BPMA analyses are consistent and failed in regions where $D / T \geq 15$. This is due to the extreme scatter in the measured $T$ rate for multiplicity analysis. The BPMA fails in this region due to the ratio of $\mathrm{D} / \mathrm{T}$ being outside the calibrated range. 


\begin{tabular}{|c|c|c|c|c|c|c|}
\hline \multicolumn{7}{|c|}{ Table XV. } \\
\hline \multirow[t]{2}{*}{ Matrix } & \multirow{2}{*}{$\begin{array}{c}\text { Singles } \\
\text { (counts/s) }\end{array}$} & \multirow{2}{*}{$\begin{array}{c}\text { Doubles } \\
\text { (counts/s) }\end{array}$} & \multirow{2}{*}{$\begin{array}{c}\text { Triples } \\
\text { (counts/s) }\end{array}$} & \multicolumn{3}{|c|}{ Add-a-Source } \\
\hline & & & & $\bar{\delta}$ & $\overline{D_{c}}$ & $\mathrm{~m}_{\mathrm{Pu} 240 \mathrm{c}}$ \\
\hline Empty drum & 243.0 & 37.40 & 3.80 & 0.000 & 36.93 & 0.686 \\
\hline $\mathrm{CH}_{2}$ Cylinder & 242.0 & 29.12 & 2.38 & 0.002 & 28.82 & 0.536 \\
\hline $\mathrm{CH}_{2} \mathrm{Cyl}$ + 1-gal. beads & 208.4 & 18.93 & 1.46 & 0.020 & 19.09 & 0.355 \\
\hline $\mathrm{CH}_{2} \mathrm{Cyl} .+$ poly blocks & 183.1 & 13.72 & 0.71 & 0.045 & 14.17 & 0.263 \\
\hline $\begin{array}{l}\mathrm{CH}_{2} \mathrm{Cyl}+\text { more poly } \\
\text { blocks }\end{array}$ & 136.8 & 7.34 & 0.24 & 0.157 & 8.38 & 0.156 \\
\hline $\mathrm{CH}_{2}$ Cyl. $+22-\mathrm{kg}$ beads & 127.1 & 6.01 & 0.09 & 0.161 & 6.89 & 0.128 \\
\hline \multirow{2}{*}{\multicolumn{2}{|c|}{ Matrix }} & \multicolumn{2}{|l|}{ Multiplicity } & \multicolumn{3}{|l|}{ BPMA } \\
\hline & & efficiency & $\mathrm{m}_{\mathrm{Pu} 240 \mathrm{e}}$ & $\Delta \mathrm{y}_{\mathrm{D}}$ & $\overline{D_{C}}$ & $\mathrm{~m}_{\mathrm{Pu} 240 \mathrm{e}}$ \\
\hline Empty drum & & 0.280 & 0.788 & 0.0858637 & 40.611303 & 0.7548569 \\
\hline $\mathrm{CH}_{2}$ Cylinder & & 0.225 & 0.948 & 0.6321043 & 47.526878 & 0.8833992 \\
\hline $\mathrm{CH}_{2} \mathrm{Cyl}+$ +1-gal. beads & & 0.213 & 0.692 & 0.9281579 & 36.500029 & 0.6784392 \\
\hline $\mathrm{CH}_{2} \mathrm{Cyl} .+$ poly blocks & & 0.143 & 1.115 & -4.330617 & -45.696065 & -0.8493692 \\
\hline $\begin{array}{l}\mathrm{CH}_{2} \mathrm{Cyl}+\text { more poly } \\
\text { blocks }\end{array}$ & & 0.090 & 1.481 & -1.5767002 & -4.2329796 & -0.0786799 \\
\hline $\mathrm{CH}_{2}$ Cyl. $+22-\mathrm{kg}$ beads & & 0.041 & 5.963 & -1.1536457 & -0.9234107 & -0.0171638 \\
\hline
\end{tabular}

A second set of data were taken to systematically explore local shielding. These were performed with the highly attenuating matrices of the Poly Beads/Vermiculite/Borax (PBV) mixture, Poly Beads, and Borated Poly Blocks. The data from these runs are presented in Table XVI. 


\begin{tabular}{|l|c|c|c|c|c|c|c|c|}
\hline \hline \multicolumn{7}{|c|}{ Table XVI. Diversion Scenario Test 2 Data from HENC } \\
\hline Sample & Source Position & $\begin{array}{c}\text { Singles } \\
\text { (counts/s) }\end{array}$ & $\begin{array}{c}\text { Doubles } \\
\text { (counts/s) }\end{array}$ & $\begin{array}{c}\text { Triples } \\
\text { (counts/s) }\end{array}$ & delta & Pos 1 & Pos 2 & Pos 3 \\
\hline Empty Drum & $\begin{array}{c}\text { Two-thirds R, } \\
\text { half H }\end{array}$ & 245.156 & 37.354 & 3.891 & 0.006 & 0.996 & 1.007 & 1.016 \\
\hline $\begin{array}{c}\text { Two-thirds R, } \\
\text { half H }\end{array}$ & 245.622 & 37.473 & 4.025 & 0.004 & 1.000 & 1.015 & 0.996 \\
\hline Empty Drum & $\begin{array}{c}\text { Two-thirds R, } \\
\text { half H }\end{array}$ & 246.026 & 37.667 & 4.177 & -0.003 & 0.994 & 0.999 & 0.998 \\
\hline Poly Beads/Verm & Top - Center & 206.737 & 23.033 & 1.955 & 0.443 & 1.438 & 1.469 & 1.423 \\
\hline Poly Beads/Verm & Top - Center & 208.926 & 22.674 & 1.831 & & & & \\
\hline Poly Beads/Verm & $\begin{array}{c}\text { Center - 5 in. } \\
\text { down }\end{array}$ & 183.937 & 15.420 & 1.089 & & & & \\
\hline Poly Beads/Verm & $\begin{array}{c}\text { Center - 5 in. } \\
\text { down }\end{array}$ & 182.847 & 15.180 & 1.008 & & & & \\
\hline Poly Beads/Verm & $1 / 2$ R, 5 in. down & 196.496 & 18.240 & 1.303 & & & & \\
\hline Poly Beads/Verm & Edge, 6 in. down & 224.096 & 27.887 & 2.678 & 0.476 & 1.487 & 1.487 & 1.455 \\
\hline Poly Beads & Top - Center & 179.660 & 15.807 & 1.103 & 0.489 & 1.238 & 1.404 & 2.020 \\
\hline Poly Beads & Top - Center & 184.759 & 16.977 & 1.180 & & & & \\
\hline Poly Block & In block & 193.270 & 22.488 & 1.973 & 0.030 & 1.025 & 1.022 & 1.043 \\
\hline 3 Poly Blocks & In block & 118.993 & 8.244 & 0.422 & & & & \\
\hline 3 Poly Blocks & In block & 118.707 & 8.333 & 0.449 & 0.090 & 1.052 & 1.079 & 1.144 \\
\hline 13 Poly Blocks & Center of blocks & 31.257 & 0.535 & -0.021 & 0.251 & 1.128 & 1.207 & 1.465 \\
\hline 13 Poly Blocks & Center of blocks & 31.363 & 0.611 & 0.021 & 0.256 & 1.130 & 1.230 & 1.448 \\
\hline 13 Poly Blocks & Outer block & 82.650 & 4.142 & 0.186 & 0.250 & 1.134 & 1.205 & 1.453 \\
\hline
\end{tabular}

The repeat runs were summed, and the three analysis methods were performed on the data with results given in Table XVII. The PBV data show that the location of the source affects the results. If the source is placed on top or the edge of the material, the AS overcorrects. Placing the source partially into the materials results in an underestimation of the mass. The multiplicity analysis gives results which are within $10 \%$ and detection efficiencies that change by eight percentage points. The BPMA method gives results which are consistently higher than the multiplicity analysis and fail for PBV-III. The large discrepancies can be attributed to the cases for which D/T approach 15 . The AS and multiplicity analysis do reasonably well for the poly beads. The BPMA method is getting close to the D/T limit of 15 . 


\begin{tabular}{|c|c|c|c|c|c|c|c|c|c|}
\hline \multirow{3}{*}{ Matrix } & & ble & III. & $n$ & Scenario $\mathrm{Te}$ & Resul & & & \\
\hline & \multirow{2}{*}{$\begin{array}{c}\text { Doubles } \\
{[\text { Counts/s] }}\end{array}$} & \multicolumn{3}{|c|}{ Add-a-Source } & \multirow{2}{*}{\begin{tabular}{|c|} 
Multiplicity \\
eff \\
\end{tabular}} & \multirow{2}{*}{\begin{tabular}{|l|}
$\mathrm{m}_{\mathrm{Pu} 240 \mathrm{c}}$ \\
\end{tabular}} & \multicolumn{3}{|l|}{ BPMA } \\
\hline & & $\delta$ & $\mathrm{D}_{\mathrm{C}}$ & $\mathrm{m}_{\mathrm{Pu} 240 \mathrm{c}}$ & & & $\Delta \mathrm{y}_{\mathrm{D}}$ & $\mathrm{D}_{\mathrm{C}}$ & $\mathrm{m}_{\mathrm{Pu} 240 \mathrm{c}}$ \\
\hline Empty Drum & 37.498 & 0.002 & 37.498 & 0.697 & 0.296 & 0.707 & 0.012 & 37.93 & 0.705 \\
\hline PBV-I & 22.854 & 0.443 & 41.045 & 0.763 & 0.228 & 0.726 & 1.213 & 40.23 & 0.748 \\
\hline PBV-II & 15.420 & 0.443 & 27.694 & 0.515 & 0.195 & 0.673 & 1.741 & 42.26 & 0.786 \\
\hline PBV-III & 15.180 & 0.443 & 27.263 & 0.507 & 0.183 & 0.749 & 3.017 & 60.97 & 1.133 \\
\hline PBV-IV & 18.240 & 0.443 & 32.759 & 0.609 & 0.197 & 0.778 & 1.593 & 47.30 & 0.879 \\
\hline PBV-V & 27.887 & 0.476 & 54.184 & 1.007 & 0.265 & 0.658 & 0.180 & 32.91 & 0.612 \\
\hline Poly Beads & 16.392 & 0.489 & 32.899 & 0.612 & 0.192 & 0.735 & 1.949 & 48.35 & 0.899 \\
\hline Poly Block & 22.488 & 0.030 & 22.893 & 0.426 & 0.242 & 0.636 & 0.388 & 31.21 & 0.580 \\
\hline 3 Poly Blocks & 8.289 & 0.090 & 8.910 & 0.166 & 0.145 & 0.655 & -5.005 & -33.24 & -0.618 \\
\hline 13 PB-I & 0.573 & 0.254 & 0.728 & 0.014 & -0.007 & 0.094 & -1.229 & -0.15 & -0.003 \\
\hline 13 PB-II & 4.142 & 0.250 & 5.240 & 0.097 & 0.124 & 0.447 & -2.472 & -6.10 & -0.113 \\
\hline
\end{tabular}

Note: PBV-I: Top Center, PBV-II: Center 5 in. down, PBV-III: Center 6 in. down, PBV-IV: half R, PBV-V: Edge filled half way

The PBV drum was replaced with a drum half full with polyethylene beads. The AS results in a mass which is within $15 \%$, the multiplicity within $10 \%$. The BPMA fails as it is past the D/T limit of 15 . The AS method does show the effects of the half-full barrel in the three positions. Although the average is 1.489 for the three positions, the lowest position on the barrel (position 3 ) gives a ratio of $\approx 2$, which indicates a highly attenuating material. Location of the source relative to the material would greatly affect the measured value. The AS perturbation is $\delta=1$ which is outside the calibration range of the AS technique.

The last measurements considered different configurations of the FZC-158 source and boron-loaded polyethylene blocks $\left({ }^{10} \mathrm{~B}\right.$ captures thermal neutrons). The blocks are $5 \mathrm{~cm} \times 10 \mathrm{~cm} \times 20 \mathrm{~cm}$ in size. One of the blocks had a hole machined out to accommodate the FZC-158 source to be centrally located. The first setup considers the source and the single block. The AS method underestimates the mass due to the relatively small size of the block. The AS and multiplicity analysis both result in lower mass, which is not only compounded by the shielding, but also the location of the source. The BPMA is within $20 \%$ of the correct value. A poly block is placed underneath and on top of the source containing the block.

For this three-block configuration, the AS underestimates the mass by a factor of 6 . The multiplicity analysis results in a mass which is within $10 \%$ but at a reduced efficiency. The BPMA fails for this and the additional cases.

Thirteen blocks of poly are stacked within the sample drum to about two-thirds height. The source block is placed in the center of the drum and the center of the three layers. Although all three methods fail to give the correct mass, the three together give a useful picture as to the possible effects of shielding. 
An additional "flag" for anomalous drums may be generated from the D/T ratio. From Eq. (5),

$$
\frac{D}{T}=3\left(\frac{\mathrm{f}_{\mathrm{D}}}{\mathrm{f}_{\mathrm{T}}}\right)\left(\frac{v_{\mathrm{s} 2}}{v_{\mathrm{s} 3}}\right)\left(\frac{1}{\varepsilon}\right) \propto \frac{1}{\varepsilon} .
$$

As the amount of shielding increases, the efficiency for detection decreases, causing an increase in the $\mathrm{D} / \mathrm{T}$ ratio.

\section{CONCLUSIONS}

The purpose of this work was to consider three analysis techniques for applications to waste and diversion of material. The data used in the analysis were taken using the HENC with the ${ }^{252} \mathrm{Cf}$ AS feature. All three methods of analysis bring an additional piece to the assay of an "unknown" barrel.

\section{A. Waste}

The data and results presented in the previous sections point to the AS feature as the overwhelming candidate for the measurement of drums containing a wide range of matrices. The AS technique is limited only by the fact that it assumes that the plutonium is not all concentrated at the center or perimeter of the drum. The AS relies on creating matrix drums to calibrate over the desired range of perturbations. The multiplicity analysis adds to the information on the drum. It may be applicable in determining whether a sample is undergoing self-multiplication, a nonuniform source distribution, or a high $(\alpha, n)$ rate. The BPMA method has reduced errors in some regions compared to the multiplicity method. Additional comparisons are needed to map the possible applications, especially for cases with a higher $(\alpha, \mathrm{n})$ rate.

\section{B . Diversion Scenarios}

The AS method fails to measure mass properly if all of the plutonium is concentrated in a localized neutron shield. In some cases the difference in the AS perturbation at the three positions may be used to flag possible diversions or problem drums. The position of the source and the attenuating matrix are not discernible with this technique. The source may or may not be within the matrix in question.

Multiplicity analysis can deal with these cases, but requires counting time which may be prohibitive. In addition to the mass reported by the technique, efficiency and $\alpha$ are given.

For some cases, the BPMA analysis resulted in an uncertainty less than that produced by multiplicity analysis for the equivalent counting time. The $\mathrm{D} / \mathrm{T}$ ratio may be more applicable and easier to implement than the BPMA method for flagging a possible diversion. The ratio is proportional to the efficiency for detecting the neutrons from their point of origination. The BPMA method, however, requires further study, and additional calibration data sets would improve the relationship. All three measurements in conjunction would provide a series of software tests pointing to barrels which need additional analysis or closer scrutiny. 


\section{REFERENCES}

1. H. O. Menlove, D. H. Beddingfield, M. M. Pickrell, D. R. Davidson, R. D. McElroy, and D. B. Brochu, "The Design of a High Efficiency Neutron Counter for Waste Drums to Provide Optimized Sensitivity for Plutonium Assay," Los Alamos National Laboratory document LA-UR-96-4585 (1986).

2. H. O. Menlove, J. Baca, and J. Pecos, "HENC Performance Evaluation and Plutonium Calibration," Los Alamos National Laboratory report LA-13362-MS.

3. HENC Hardware Manual, under preparation from Canberra Industries, Inc., Livermore, California (to be published in 1998).

4. H. O. Menlove, J. Baca, W. Harker, K. E. Kroncke, M. C. Miller, S. Takahashi, H. Kobayashi, S. Seki, K. Maysuyama, and S. Kobayashi, "WDAS Operation Manual Including the Add-A-Source Function," Los Alamos National Laboratory report LA12292-M (1992).

5. M. S. Krick and W. S. Harker, "Multiplicity Neutron Coincidence Counting User's Manual," Los Alamos National Laboratory report LA -UR-93-1394 (1993).

6. D. M. Cifarelli and W. Hage, "Models for a Three-Parameter Analysis of Neutron Signal Correlation Measurements for Fissile Material Assay," Nucl. Instru. and Meth. A251 550563 (1986).

7. D. Reilly, N. Ensslin, H. Smith, Jr., and S. Kreiner, "Passive Nondestructive Assay of Nuclear Materials," Los Alamos National Laboratory document LA-UR-90-732, NUREG/CR-5550 (March 1991).

8. N. Dytlewski, M. S. Krick, and N. Ensslin "Measurement Variances in Thermal-Neutron Coincidence Counting," Nucl. Instru. and Meth. A327 469-479 (1993).

9. H. O. Menlove "PDP Drum Results Using NCC Software," Los Alamos National Laboratory memorandum, NIS-5-96-691, to Dan Taggart, December 9, 1996. 